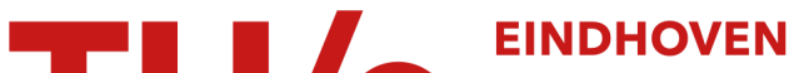 UNIVERSITY OF TECHNOLOGY
}

\section{Mood measurement with Pick-A-Mood}

\section{Citation for published version (APA):}

Desmet, P. M. A., Vastenburg, M. H., \& Romero, N. (2016). Mood measurement with Pick-A-Mood: Review of current methods and design of a pictorial self-report scale. Journal of Design Research, 14(3), 241-279. https://doi.org/10.1504/JDR.2016.079751

DOI:

10.1504/JDR.2016.079751

Document status and date:

Published: 01/01/2016

\section{Document Version:}

Accepted manuscript including changes made at the peer-review stage

\section{Please check the document version of this publication:}

- A submitted manuscript is the version of the article upon submission and before peer-review. There can be important differences between the submitted version and the official published version of record. People interested in the research are advised to contact the author for the final version of the publication, or visit the $\mathrm{DOI}$ to the publisher's website.

- The final author version and the galley proof are versions of the publication after peer review.

- The final published version features the final layout of the paper including the volume, issue and page numbers.

Link to publication

\section{General rights}

Copyright and moral rights for the publications made accessible in the public portal are retained by the authors and/or other copyright owners and it is a condition of accessing publications that users recognise and abide by the legal requirements associated with these rights.

- Users may download and print one copy of any publication from the public portal for the purpose of private study or research.

- You may not further distribute the material or use it for any profit-making activity or commercial gain

- You may freely distribute the URL identifying the publication in the public portal.

If the publication is distributed under the terms of Article 25fa of the Dutch Copyright Act, indicated by the "Taverne" license above, please follow below link for the End User Agreement:

www.tue.nl/taverne

Take down policy

If you believe that this document breaches copyright please contact us at:

openaccess@tue.nl

providing details and we will investigate your claim. 


\title{
Mood Measurement with Pick-A-Mood \\ Review of current methods and design of a pictorial self-report scale
}

\author{
Pieter Desmet*, Martijn Vastenburg ${ }^{1}$ and Natalia Romero \\ Delft University of Technology \\ Faculty of Industrial Design Engineering \\ Landbergstraat 15 \\ 2628 CE Delft, The Netherlands \\ ${ }^{1}$ Eindhoven University of Technology \\ School of Innovation Sciences \\ Human-Technology Interaction Group \\ IPO 1.20, De Saale, 5612 AJ, Eindhoven \\ Email: p.m.a.desmet@tudelft.nl \\ Email: m.h.vastenburg@tue.nl \\ Email: n.a.romero@tudelft.nl \\ ${ }^{*}$ Corresponding author
}

\begin{abstract}
This paper introduces Pick-A-Mood, a character-based pictorial scale for reporting and expressing moods. Pick-AMood consists of three characters that each express eight mood states, representing four main categories: Excited and Cheerful (for energized-pleasant), Irritated and Tense (for energized-unpleasant), Relaxed and Calm (for calmpleasant), and Bored and Sad (for calm-unpleasant). Using Pick-A-Mood requires little effort on the part of respondents, making it suitable for design research applications in which people often have little time or motivation to report their moods. Contrary to what is often assumed, mood and emotion are distinct phenomena with different measurable manifestations. These differences are discussed, and a review of existing methods is provided, indicating to what extent current methods that measure emotion are suitable for measuring mood. The development and validation of Pick-A-Mood is reported, and application examples and research opportunities are discussed.
\end{abstract}

Keywords: mood measurement, design for mood, measurement method review.

Reference to this paper should be made as follows: Desmet, P.M.A., Vastenburg, M.H., and Romero, N. (2016) 'Mood measurement with Pick-A-Mood: Review of current methods and design of a pictorial self-report scale', J. Design Research, Vol. xx, No. xx, pp. xx-xx.

Bibliographical notes:

Prof. Dr. Pieter Desmet is chair of the Design for Experience research group and programme director of the Design for Interaction master's programme at the Faculty of Industrial Design Engineering at Delft University of Technology. His main research interests are in the fields of design, emotion, and subjective well-being. Desmet is a board member of the international Design \& Emotion Society and co-founder of the Delft Institute of Positive Design. 
Dr. Martijn Vastenburg is founder and CEO of ConnectedCare, and is part-time assistant professor at the HumanTechnology Interaction group at Eindhoven University of Technology. Until 2012, he worked as assistant professor in Industrial Design Engineering at Delft University of Technology. His research interests are in the fields of design methodology, persuasive technology, digital care collaboration, group awareness and social connectedness. He works in the crossover between health innovation and design, and he has a business-oriented mindset in design research.

Dr. Natalia Romero Herrera works as an assistant professor in the Industrial Design Engineering Faculty at Delft University of Technology. She is an experienced UX/HCI design researcher who dedicates her research and education time to developing knowledge and teaching about living labs methodologies in the context of home and work environments. Romero Herrera's main research line aims to supports participants as active collaborators in the design process of innovative sustainable technologies. She investigates how to empower participants in their ability to understand, experiment with and assess the subjective and objective impact of their daily practices.

\section{Introduction}

Mood provides the affective colouring for all of our day-to-day events and interactions: when cheerful, we see the world through rose-coloured glasses, and when gloomy, we see the same world - and everything in it - as dim and grey (Morris, 1989). In previous work, we have proposed that there are at least three reasons why the phenomenon of mood is relevant to the discipline of design (viz. Desmet, 2008, 2015). Firstly, insight into mood can be useful for those wanting to better understand how design can influence consumer behaviour. When purchasing products and services, people's preferences are influenced by their momentary mood states (Maier et al., 2012; Quartier, et al., 2009). Moreover, mood affects a person's general purchase willingness (Arnold \& Reynolds, 2009) and post-purchase product evaluations (Gorn et al., 1993; Miniard et al., 1992). Secondly, insight into mood can help designers seeking to optimise userproduct interactions, as mood influences which products people choose to interact with (Djamasbi \& Strong, 2008; Djamasbi et al., 2010), how they want to interact with these products (Wensveen, 2005), which interaction possibilities they explore (Venkatesh \& Speier, 1999), and what kinds of information they process during interaction (Zhang \& Jansen, 2009). Thirdly, insight into mood is useful when designing with the intention to promote user happiness. A positive mood balance is a key determinant of well-being (Morris, 1999), while a lasting disturbance of this balance is one of the main causes of human ill-being (e.g., Peeters et al., 2006).

Given its pervasive influence on user preferences, behaviour, and general well-being, it is not surprising that human mood has been a prominent source of inspiration in many design disciplines. Designers and design researchers have explored a wide variety of applications for mood-inspired design (for a recent overview, see Desmet, 2015). The domain's broadness is illustrated with some examples in Figure 1. Interior designers have explored how ambient technology can be used to develop moodsensitive interiors: a recent example is the Adaptive Relaxation Space, an interactive space in which the colour, light intensity and spatial configuration dynamically adapt to stimulate a guided and gradual mood transition (Figure 1a; Van de Garde, 2014). Similar mood-sensitive ambiance controls are being increasingly implemented in retail and hospitality design. For example, airline companies like Virgin Atlantic and Singapore Airlines use dynamic ambient light in an attempt to influence passengers' moods (Holland, 2011), and the CitizenM hotel in Amsterdam provides their guests with an ambient controller to personalise their room's lighting, temperature, curtain and soundtrack settings according to their mood (Figure 1b; Mood-Pad; Philips, 2008). 


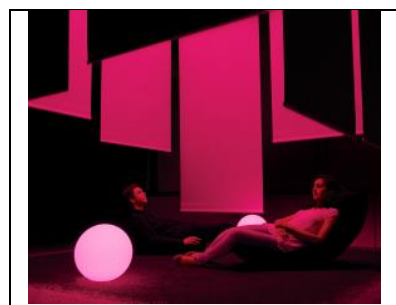

a - Influence mood

(Van de Garde, 2014)

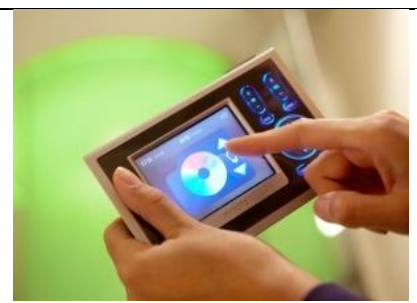

b - Mood ambiance

(Philips, 2008)

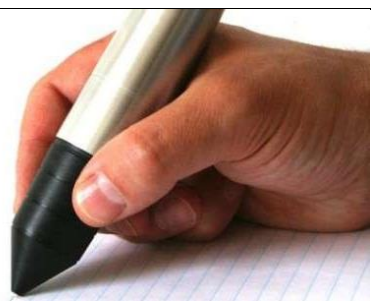

c - Capture mood

(Alonso et al., 2008)

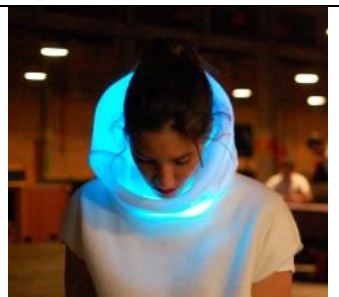

d - Express mood

(Stylios \& Yang 2013)

Figure 1. Four examples of mood in the context of design.

Many mood-inspired design explorations utilize some form of real-time mood measurement, either via sensors that measure (psycho-) physiological signals with wearable devices like wristbands or rings, or through behavioural expressions, such as body posture, mouse movements, or hand movement when using a pen (Figure 1c; Alonso et al., 2008). Using digital technology, such dynamic mood data is transformed into meaningful expressions; examples include coloured light in garments (Figure 1d; MoodWear; Stylios \& Yang 2013), and dynamic surface textures in interior architecture (Textile Mirror, Davis et al., 2013). Other initiatives explore how dynamic mood data can support interpersonal interactions. El Kaliouby and colleagues (2006), for example, developed 'social-emotional prosthetics' that are intended to support mood-sensitive communication. Others have explored how mood data can be used to support a user's personal mood awareness. Examples are affective wearables that stimulate personal development by providing real-time, personalized mood feedback (e.g., Mood-Wings by MacLean et al., 2013), and a host of apps (e.g. Moody-Me, MyMoodTracker, or MoodChart) that support users' mood awareness by visualising longitudinal mood data.

Many of these initiatives rely on an ability to measure mood. Mood measurement is used, for example, to determine people's moods in a usage context, or to validate intended user mood effects of new concepts. In addition, mood measurement techniques are increasingly applied in domains such as health (e.g., McDuff et al., 2012) and communication (e.g., Church et al., 2010). We propose that this emerging domain of mood-sensitive design can be strengthened with effective and reliable instruments dedicated to measuring mood. The present work focuses on the question of how mood can be measured in the context of design research. Note that a vast number of emotion-measuring instruments exist, ranging from traditional questionnaires to methods that track emotion in real-time by measuring expressive or physical manifestations of emotions. We observed that these methods have also been frequently used to measure mood. It is, however, important to realize that instruments that measure emotions are not always suitable for measuring mood as well. To support this proposition, we first discuss the key features of the mood phenomenon, addressing differences between mood and emotion. This comparison serves as the foundation for an overview of available methods used to measure affect in design research, and a discussion of the suitability of these methods for mood measurement. The overview provides the basis for the development of Pick-A-Mood, a pictorial scale for the self-report of eight distinct mood states. ${ }^{i}$ Even though Pick-a-Mood was developed with design and design research in mind, it has a broad applicability because it measures human moods that are universal. The method's development and validation is reported, some initial examples of applications are presented, and future developments are discussed. 


\section{Mood versus emotion}

The words mood and emotion are often used interchangeably, in everyday language as well as in scholarly writings. This indiscriminate choice of words seems to suggest that mood and emotion are different words that express a single phenomenon. Indeed, they do share an important feature: both are valenced affective responses, that is, they involve a perceived goodness or badness, pleasantness or unpleasantness. When we are angry (emotion) or grumpy (mood) we feel bad, and when we are proud (emotion) or cheerful (mood), we feel good. Russell (1980; 2003) introduced the concept of 'core-affect' by combining the valence dimension with physiological arousal into a two-dimensional model of affect (Figure 2). According to Russell, the experience of core-affect is a single integral blend of these two dimensions.

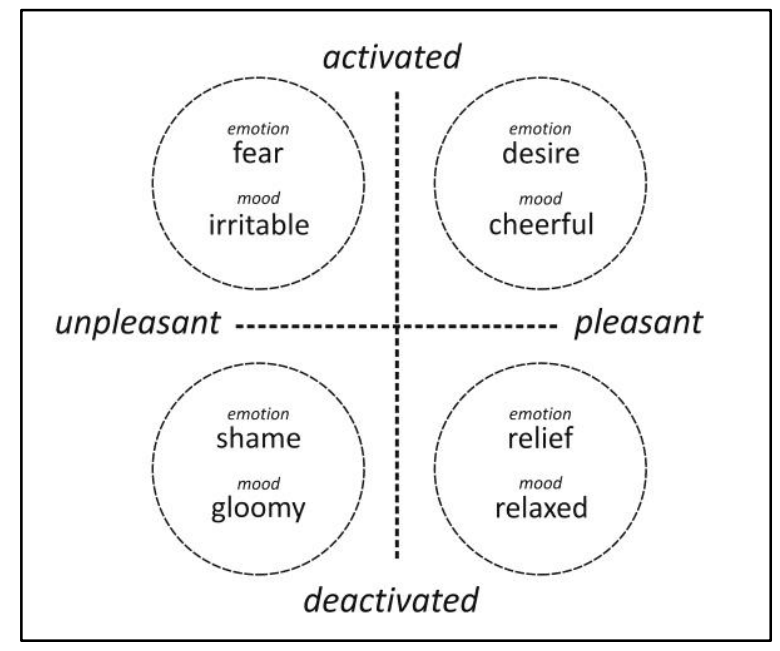

Figure 2. Two dimensions of core-affect, with examples of emotions and moods.

The horizontal axis in Figure 2 represents valence (ranging from unpleasant to pleasant), and the vertical axis represents arousal (ranging from deactivated to activated). These two dimensions apply to both mood and emotion. Cheerful (mood) and desire (emotion), for example, are both activated-pleasant affect states. Likewise, irritable (mood) and disgust (emotion) are both activated-unpleasant affect states. Even though both mood and emotion can be described in terms of valence and arousal, they are distinct and unique phenomena that differ in two vital ways: in terms of (1) their causes and (2) their experiential and behavioural manifestations. Table 1 provides vignette examples, highlighting the key differences between mood and emotion, and focusing on those manifestations that are often used as the basis for affect measurement.ii

Table 1. Emotion versus mood manifestations

\begin{tabular}{lll}
\multicolumn{2}{c}{ Table 1. Emotion versus mood manifestations } \\
\hline EMOTION & MOOD \\
\hline $\begin{array}{l}\text { Positive } \\
\text { example }\end{array}$ & $\begin{array}{l}\text { Pride: "When preparing my midterm } \\
\text { presentation, I suddenly discovered that } \\
\text { my group performed much better than I } \\
\text { had initially concluded. That's fantastic; } \\
\text { my team is the best!" }\end{array}$ & $\begin{array}{l}\text { Cheerfulness: "The sun is out; I managed } \\
\text { to submit my report, had a wonderful } \\
\text { lunch, and I'm looking forward to the } \\
\text { weekend. Now I have to attend this } \\
\text { meeting - I 'Il just sit back and enjoy." }\end{array}$ \\
\hline Negative & Fear: "I had no idea I was supposed to & Grumpiness: "I didn't sleep well last night; \\
\hline
\end{tabular}




\begin{tabular}{|c|c|c|}
\hline example & $\begin{array}{l}\text { present the midterm results. I only have } 10 \\
\text { minutes to prepare before the meeting } \\
\text { starts. Oh dear, where did I store the } \\
\text { data?" }\end{array}$ & $\begin{array}{l}\text { my son was nagging, the coffee dispenser } \\
\text { was out of order, and I have too many } \\
\text { things on my plate. And now I have to be } \\
\text { in a meeting that I don't even find } \\
\text { relevant." }\end{array}$ \\
\hline Feeling & $\begin{array}{l}\text { Short duration (seconds or minutes). } \\
\text { Rapid onset and episodic. } \\
\text { Often high intensity. }\end{array}$ & $\begin{array}{l}\text { Long duration (hours or days). } \\
\text { Gradual onset and continuous. } \\
\text { Often low intensity. }\end{array}$ \\
\hline Focus & $\begin{array}{l}\text { Specific and targeted. } \\
\text { External (outward focus). } \\
\text { Response to a single cause. }\end{array}$ & $\begin{array}{l}\text { Global and diffuse. } \\
\text { Internal (inward focus). } \\
\text { Response to cumulative causes. }\end{array}$ \\
\hline Impact & $\begin{array}{l}\text { (Re)directs thought and behaviour. } \\
\text { Stimulates a specific adaptive response. } \\
\text { Strong physiological impact. }\end{array}$ & $\begin{array}{l}\text { Shapes ongoing thought and behaviour. } \\
\text { Has a global influence on all responses. } \\
\text { Mild physiological impact. }\end{array}$ \\
\hline
\end{tabular}

\section{Feeling}

Moods last longer than emotions. Emotions are acute, and exist only for a relatively short period of time, usually seconds, minutes, or several hours at most (Verduyn, Van Mechelen, \& Tuerlinckx, 2011). Moods, on the other hand tend to have a relatively long-term nature. One can be sad or cheerful for several days or even weeks (Beedie et al., 2005). In fact, even though it may not always be in our awareness, moods are always present. In that sense, moods are the affective background colour of what we do, while emotions are momentary 'perturbations' that are superimposed on this affective background (Davidson, 1994). Moods often feel like milder or diluted versions of emotions. For instance, an irritable mood can feel like a mild form of the emotion anger, cheerfulness like a mild joy, gloominess like a mild sadness, and nervousness like a mild fear (Prinz, 2004).

\section{$\underline{\text { Focus }}$}

Emotions are specific and targeted, while moods are global and diffuse. Emotions always imply and involve a relation with a particular event, person or object: one is afraid of something, proud of something, in love with something and so on (Frijda, 1994). Moods are not directed at a particular object but rather at the surroundings in general or, in the words of Frijda (1994, p. 60), at 'the world as a whole'. Emotions monitor our environment, whereas our mood monitors our internal state, or the 'existential background of our lives.' (Lazarus, 1994; Morris, 1989). Emotions are typically elicited by an explicit cause (e.g. some event), while moods have combined causes (e.g., "It is raining, I didn't sleep well, and someone has finished the coffee"), and can be produced in a cumulative fashion over time. A series of mildly negative or positive experiences can produce a negative versus positive mood respectively (Davidson, 1994). Consequently, we are generally able to specify the cause of a particular emotion, but unable to specify the cause of a particular mood (Ekman, 1994).

\section{$\underline{\text { Impact }}$}

Emotions are evoked by threats (negative emotions) or opportunities (positive emotions). Because these antecedents require our immediate attention, emotion directs thought and behaviour with emotionspecific 'action tendencies' (e.g. to withdraw, attack, approach, examine, etc.) that aim to neutralize the 
threat or capitalize on the opportunity (Frijda, 1994). These action tendencies can be seen in overt and distinct (facial, vocal, bodily) expressions, and patterns of distinct autonomic changes (Izard, 1991). Contrary to emotions, moods are responses to one's general position in life (how we are doing in life overall), rather than to isolated events (Prinz, 2004). As a consequence, moods do not interrupt, but have a subtle influence on our ongoing thoughts and behaviours (Davidson, 1994); a positive mood increases, and a negative mood decreases our general 'readiness for action' in all of our ongoing undertakings. Although several emotion researchers have proposed that moods do not have distinctive expressions (see Ekman \& Davidson, 1994), it has also been suggested that moods can sometimes be observed as mild emotional expressions. For example, one who is in an irritable mood can show subtle signs of the anger expression, and someone who is in a gloomy mood can show subtle signs of the sadness expression (Ekman, 1994).

The mood-emotion comparison can be summarized in the following definitions:

- Moods are low-intensity, diffuse feeling states that can last for hours or days, have a gradual onset with cumulative antecedents, are directed at the world as a whole, and have a global and pervasive influence on one's perception and motivation.

- Emotions are high-intensity, specific feeling states that are typically short-lived, have identifiable antecedents, are directed at a particular object, and direct ongoing thoughts and behaviours.

It is important to note that rather than being independent, moods and emotions dynamically interact with each other. An accumulation of emotions can lead to particular moods (see the vignette examples in Table 1), and moods lower the threshold of emotional arousal (Davidson, 1994). When a person is in an irritable mood, for example, he or she becomes angry more readily than usual. Likewise, cheerfulness potentiates enjoyment, gloominess potentiates sadness, and oppressiveness potentiates fear (Ekman, 1994). In retail, it pays off to improve customers' moods (e.g., by looking attractive, offering drinks, making jokes and compliments, smiling) because their moods will influence their emotional response to the actual item for sale (e.g., Kelley \& Hoffman, 1997).

\section{Implications for mood measurement}

The definitions above clearly indicate that mood and emotion differ in terms of antecedents and manifestations. The difference in antecedents implies that design for emotion comes with different opportunities and challenges than design for mood (Desmet, 2015; Spillers, 2010). Equally important, the difference in manifestations implies that - contrary to what is often assumed - methods that measure emotion are not necessarily equally suitable for measuring mood. The review above suggests three categories (see also Figure 3, centre): methods that measure (1) general affect, (2) mood, or (3) emotion. Methods in the first category can measure both emotion and mood because they focus on the general dimensions of pleasantness and arousal. Methods in the second category measure distinct mood types, such as feeling grumpy, moody, cheerful, and relaxed. Methods in the third category measure distinct emotion types, such as anger, fear, joy, and admiration. The distinction between the second and third category is not always easy because the manifestations of mood and emotion types can be similar, and because many words that describe emotions are also used to describe moods. However, we argue that this overlap is not all-inclusive: while some words can describe both moods and emotions (like sad, happy, and anxious, which we call 'versatile-words'), some are primarily used to describe moods (like grumpy, 
cheerful, and tense, which we call 'mood-words'), and others are primarily used to describe emotions (like admiration, disgust, and fascination, which we call 'emotion-words'). The distinction can be made by asking the question if the word refers to an affective state that is directed at something or someone in particular. All emotion-words involve such relations to some object. Admiration, for example, is an emotion-word because it is always directed to someone or something in particular, while cheerfulness is a mood-word because it is directed at the world in general. Versatile-words have two separate (but related) meanings, and are used both for moods and emotions. This means that methods that measure mood should include only versatile- and/or mood words in procedures and/or data reporting, and methods that measure emotion should include only versatile- and/or emotion-words.

\section{Methods to measure mood and emotion}

An overview of methods that are used to measure mood and emotion in the context of design and design research is provided in the section below. This overview aims for breadth more than depth: it demonstrates the variety of approaches that is currently available ${ }^{\mathrm{iii}}$. The main aim is to explore the degree to which the available methods are suitable for measuring mood, using the categorisation that was proposed in the previous section. Scholars who introduce and/or use mood or emotion measurement methods are often not precise when describing the object of study. As a consequence, many methods that are reported to measure mood in fact measure emotions, or general affect, and vice versa. For this reason, we based our clustering on the mood and emotion definitions provided in the previous section. Figure 3 provides an overview of the methods that are included in the review, grouped into four clusters that differ in terms of what they measure. A complete list of self-report methods included in the review can be found in Appendix 1 (verbal scales) and Appendix 2 (pictorial scales). Methods in the cluster 'mood types' measure distinct moods, such as feeling grumpy, moody, cheerful, and relaxed. Methods in the cluster 'emotion types' are similar, but measure emotions, such as anger, fear, joy, and admiration. Those in 'mood \& emotion types' are less focused, measuring a variety of both moods and emotions. The fourth and final cluster, 'affect factors', includes methods that measure general underlying factors (or general dimensions) of affect that apply to both emotions and moods. 


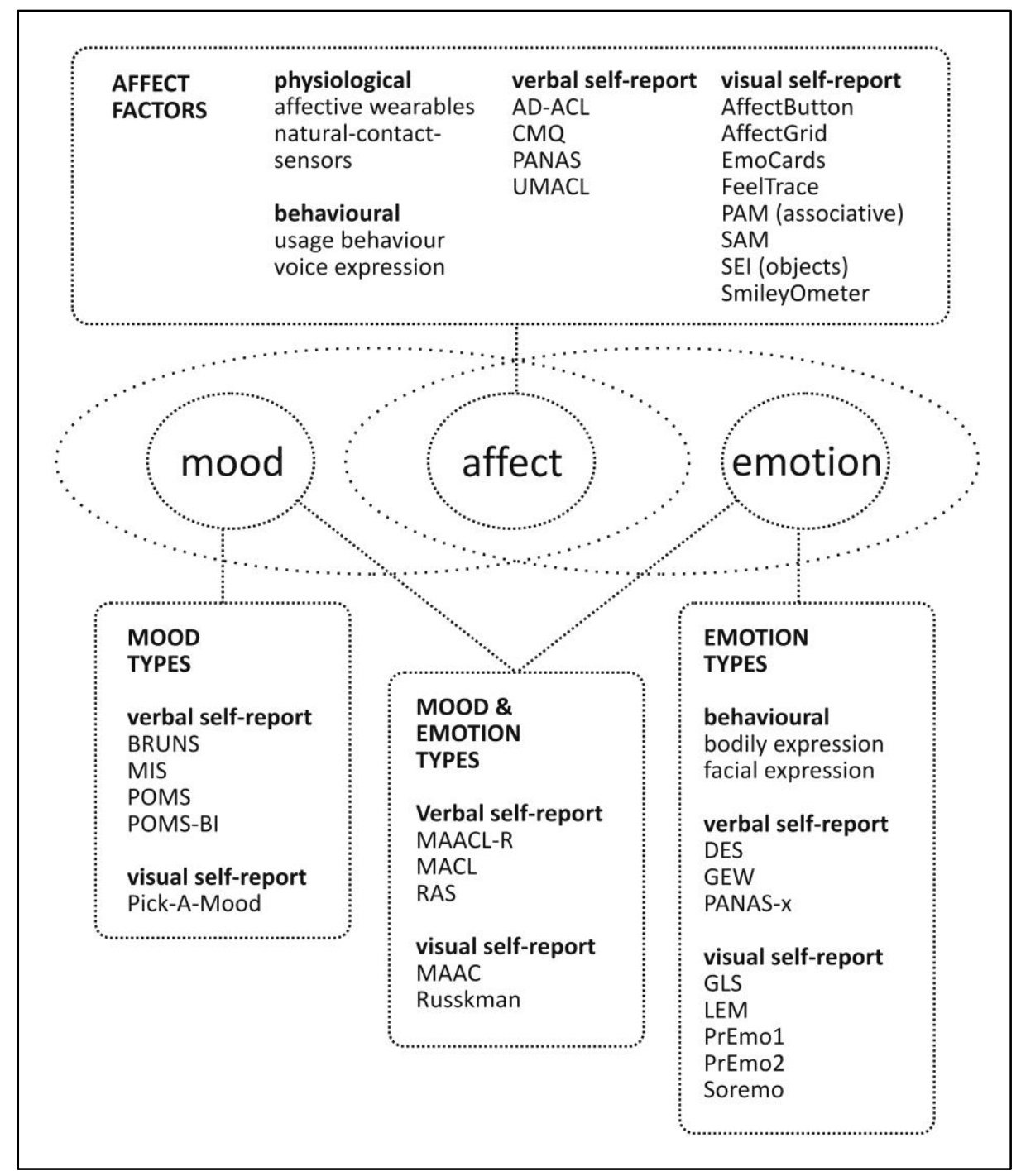

Figure 3. Four clusters of affect measurement methods.

Methods not only differ in terms of what affective state they measure, but also in terms of how they measure mood or emotion. Two broad categories can be distinguished. The first represents methods that rely on some kind of automatic affect recognition. These are methods that measure objective signals that are believed to represent moods and emotions. They are inspired by theories that highlight the embodiment of affect, proposing that emotions are represented by specific physiological and behavioural response patterns (Ekman et al., 1983; Ekman, 1992). The other category represents methods that rely on some type of self-report. Traditionally, these are questionnaires that include lists of verbal adjectives. Besides these verbal questionnaires, there is a (growing) category of non-verbal self-report methodology using pictorial scales. Below, we review specific automatic affect recognition instruments (physiological and behavioural) and self-report methods (verbal and pictorial), providing example methods for each category and discussing general strengths and limitations and applicability for the measurement of mood.

\subsection{Physiological Measures}

This category of methods is based on the proposition that physiological signals provide information about the intensity and quality of an individual's affect experiences (e.g., Ekman, Levenson, \& Friesen, 1983). 
Physiological measures make use of sensors that measure physiological activities, such as respiratory rate, muscle activity, skin conductance and temperature, or heart activity. Wearable devices with integrated sensors (sometimes called 'affective wearables'; see Picard \& Healey, 1997) come in a wide variety of forms, including (finger or ear) rings, wristbands, gloves, t-shirts and even underwear (for an overview, see Desmet, 2015). Besides such 'affective wearables', sensors can also be integrated into surfaces that users come into contact with during typical user-product interaction (sometimes called 'natural-contact sensors'; see Lin, 2011). Instead of requiring the user to wear sensors, the product 'wears' the sensors in or on its body or surface. These sensors are typically found in input devices like computer mice (see Ji, 2007; Lin, 2011; Sun et al., 2014), or car steering wheels (Cai \& Ling, 2007; Lin et al., 2007).

Three key advantages of physiological measures are that they (1) allow for continuous measurement in real-time; (2) are not intrusive to the user's experience, because they don't require the respondents to interrupt what they are doing; and (3) are not biased by cognitive or social desirability constraints. Moreover, modern affective wearables (like wrist bands) are inexpensive, unobtrusive, and allow for natural interaction, because they can be used in natural settings (e.g. Arroyo et al., 2009). A limitation of these methods is that interpreting the data is not straightforward. The ability to interpret physiological data requires specialized training, and data analysis requires time and effort due to the vide variety of factors (like mental and physical activity) apart from moods and emotions that influence the measured patterns of psychosocial signals.

\section{Mood applicability}

Existing physiological tools are able to reliably measure the arousal dimension of affect. They do not reveal valence, which implies that these methods are not able to tell the difference between states with similar arousal, like cheerful and irritable (Watson \& Tellegen, 1985). Due to rapid improvements in the accuracy of equipment and data analysis techniques, future devices may also be able to measure valance, and perhaps even some basic emotions (see Chanel et al., 2011), but this does not apply to methods that are currently available. This means that while current physiological methods can measure the arousal component of mood, they are not suitable for measuring distinct mood types.

\subsection{Behavioural Measures}

Behavioural measures are based on the proposition that emotions are represented by unique expressions (Ekman \& Friesen, 2003; Ekman, 1992) and behavioural tendencies (named "action tendencies" in psychology; Frijda, 1986). Devices have been developed to measure various modalities of expressive behaviour, such as facial and voice expression, body posture, eyelid closure patterns, or interaction behaviour when using products (e.g. mouse clicking behaviour). The most often used signal is facial expression. Traditionally, facial expressions are coded manually by trained coders, the performance of which results in reliable interpretations (see Thrasher et al., 2011), but this method is expensive, due to the time required to learn and implement it (Donato et al., 1999). Recently, researchers have begun to develop 'Automated Face Analysis' (AFA) systems that code facial expressions (see Cohn et al., 2014). Examples are the 'Computer Expression Recognition Toolbox' (CERT; Littlewort et al., 2011) and the FaceReader (see Terzis et al., 2010). One interesting approach is to count occurrences of positive and negative emotions over time as a measure for mood states (Hashemian et al., 2014). This approach is based on the proposition that mood influences the frequency of experienced positive and negative 
emotions during a day. In addition to facial expression, various basic emotions can be detected in emotional speech and in non-verbal vocal expressions (Sauter et al., 2010). Some emotions are better recognized in the face and others are better recognized in the voice (Bänziger, Patel, \& Scherer, 2014), and Sauter (2014) proposed that the voice may be a particularly important means of signalling positive affective communication. An interesting development is the measurement of emotion through body posture and movement (Bianchi-Berthouze \& Lisetti, 2002; Castellano, et al., 2008). Mota and Picard (1999) developed the Body Pressure Measurement System (BPMS), a grid of sensors inside a thin pressure pad that can be mounted on seats and backs of chairs. Chairs fitted with BPMS can be used to measure a number of emotions (D’Mello \& Graesser, 2009). A final category of methods measures affect by looking at expression in human-product interaction. Affect (stress and relaxation) can be detected from keyboard (Hernandez et al., 2014), pen (Alonso et al., 2008), mouse (Sun et al., 2014), or smartphone usage behaviours (LiKamWa et al., 2013).

The three main advantages of physiological measures also apply to behavioural measures. An additional advantage is that affect is measured using devices that do not require physical (skin-to sensor) contact between the human body and a sensor. Some can even be used without user knowledge, limiting the risk of affect being influenced by the awareness of being monitored (Picard \& Daily, 2005). Moreover, these systems are generally inexpensive, because most do not require dedicated hardware (apart from the devices developed to measure posture or interaction signals). However, the reliability of automatic detection systems for spontaneous expressions in a natural context is low (Asthana et al., 2009; Brick et al., 2009; Hoque et al., 2009). Most systems are reliable only when they are trained for each subject, therefore requiring time-consuming pre-phase processing to obtain the individual pattern of each user.

\section{Mood applicability}

The majority of behavioural measures focus on vocal or facial expressions, which have the potential to detect both emotion and mood types. However, with the current state of technology, it is not yet possible to reliably measure the subtle expressions of mood, which makes these measures primarily suitable for detecting basic emotion types (like anger, joy, and fear). Methods that focus on (interaction) behaviour are also promising, because mood theory predicts that mood has a pervasive influence on behaviour. The methods currently available can reliably measure the moods of relaxation and stress (as a bipolar construct). Other distinct moods, such as cheerful or gloomy, cannot be measured; future developments in the field may eventually make it possible to increase the palette of measurable moods.

\subsection{Verbal Self-Report Measures}

In the social sciences, a variety of verbal questionnaires and checklists have been developed to measure mood (see Coan \& Allen, 2007). A number of verbal self-report methods measure general factors or dimensions of affect. One of the most prominent is PANAS, which measures Positive Affect and Negative Affect (Watson et al., 1988). Similar well-known item-based methods are AD-ACL (Thayler, 1967), UMAC (Matthews et al., 1990), and CMQ (Barrett \& Russell, 1999) that measure four, three, and two affect factors respectively. Other methods measure distinct moods and/or emotions. POMS measures six distinct moods (McNair et al., 1971), and BRUMS measures the same moods, but with lesser items (Terry \& Lane, 2003). A significant limitation of POMS and BRUMS, however, is that they mostly focus on unpleasant moods. An updated version, POMS-BI, was developed to overcome this limitation by measuring six bipolar mood sets 
(Lorr \& McNair, 1988). MIS is a method that measures five positive and five negative moods (Mayer \& Salovey, 1988). Other methods predominantly measure emotions, such as the PANAS-X (11 emotions; Watson and Clarck, 1994), GEW (20 emotions; Scherer, 2005), and DES (10 emotions; Izard, 1993), or sets that include both moods and emotions, such as MACL (12 categories; Nowlis, 1965), MAACL-R (5 categories; Zuckerman \& Lubin, 1985), and RAS (11 categories; Russell, 1979).

The main advantage of self-report methods is that they can be used to measure subtle and distinct mood types. In addition, they are reliable and easy to administer, because they do not require dedicated instruments or training to interpret data. An important limitation is that self-report cannot be used for continuous measurement, because respondents have to interrupt their activities to record their responses. Moreover, reported responses can be biased because they rely on the respondents' ability and willingness to report their feelings. Furthermore, (especially long) item-based methods have been criticised not only for being generally burdensome and time-consuming (Curren et al., 1995), but also for requiring cognitive processing which may distort the original feelings (Poels \& Dewitte, 2006). These limitations are particularly relevant when affect is assessed in naturalistic settings, such as before or after human-product or social interaction in the context of use. In such situations, brevity is paramount (see Terry et al., 1999). It has also been noted that some items, such as the terms "bushed" and "blue" in POMS, may be susceptible to different interpretations across cultures (Grove \& Prapavessis, 1992).

\section{Mood applicability}

Questionnaires are currently the most frequently used methods to ascertain mood. They can measure subtle, nuanced mood patterns (both in terms of general underlying dimensions and in terms of distinct mood types) that currently cannot be obtained with physiological and behavioural measures (see Coan \& Allen, 2007). Although many of the questionnaires that claim to measure mood in fact measure emotions, several valid mood-specific questionnaires are available, such as POMS and BRUNS (see Figure 3).

\subsection{Pictorial Self-Report Measures}

Some of the limitations of affect questionnaires, including cognitive load, overall burden and time-tocomplete can be overcome using methods that rely on visuals instead of adjectives. Several are available that measure basic dimensions of affect, the most famous of which is SAM (Figure 4), a set of three pictorial assessment scales that measure the pleasure, arousal, and dominance associated with a person's affective state (Lang, 1980). A separate pictorial scale to measure each dimension makes self-report much less taxing in terms of time and effort. SAM is limited in that it requires considerable explanation before respondents can effectively report their feelings for each factor separately (for a discussion, see Broekens \& Brinkman, 2013). The 'Smileyometer' (Read, 2008) offers a simple emoticon-based scale that focuses on the pleasure dimension. A more sophisticated approach is the 'AffectButton' (Figure 5; Broekens \& Brinkman, 2013) that measures the same three dimensions as SAM, but with one single visual character that can vary dynamically across all three dimensions. 'EmoCards' (Desmet et al., 2001) use 16 cartoon faces to measure pleasure and arousal. 'AffectGrid' (Russel et al., 1989) and 'FeelTrace' (Cowie et al., 2000) ask respondents to point to a spot in a two dimensional space that represents a degree of pleasure and arousal. The 'Photographic Affect Meter' (Pollak et al., 2011) is based on association, asking respondents to pick one photo from a set of 16 that varies in terms of pleasantness and arousal. Unique among visuallyoriented self-report methods is the 'Sensorial Evaluation Approach' (Figure 6; SEI; Isbister et al., 2006), 
which uses eight abstract three-dimensional objects as a projective technique for qualitative affect measurement.

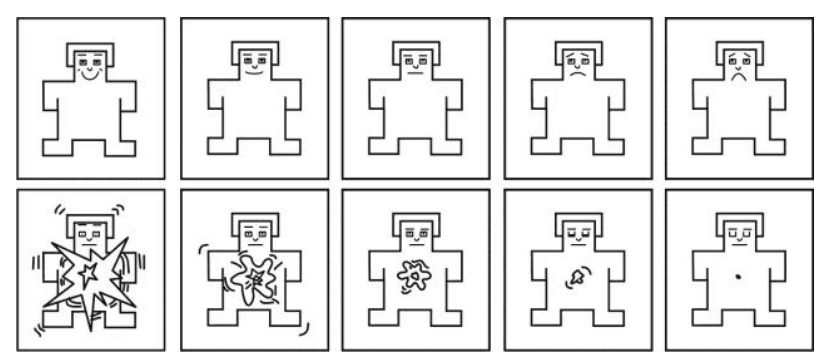

Figure 4. SAM (showing pleasantness and arousal scale; Lang, 1980).

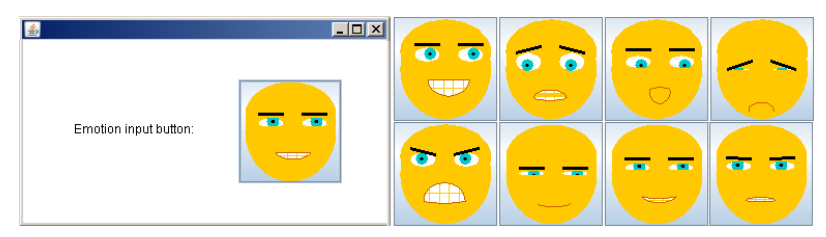

Figure 5. AffectButton (Broekens \& Brinkman, 2013).

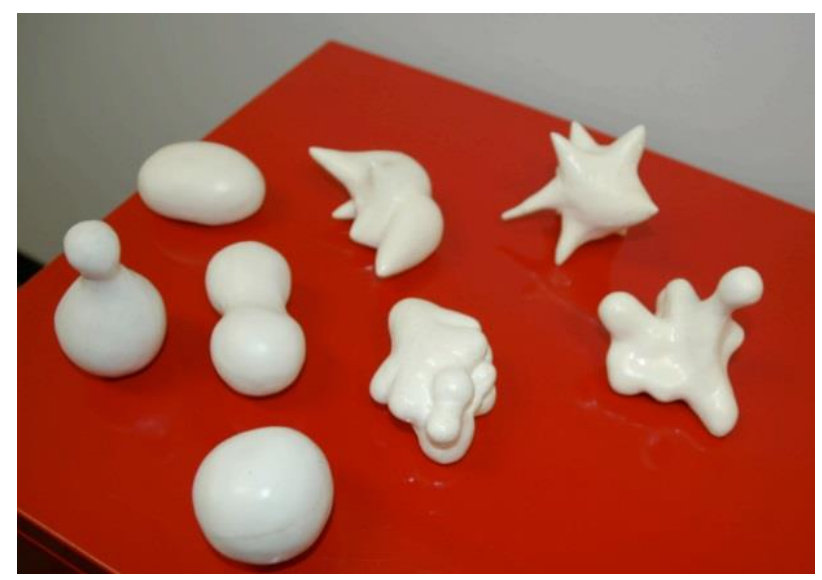

Figure 6. SEI (Isbister et al., 2007).

Beyond pictorial self-report scales that measure affective dimensions, several measurement methods have been developed that depict distinct emotions using cartoon-like illustrations. Examples that use cartoon characters are the 'Gaston Lagaffe' scale, which measures eight basic emotions (GLS; Johnstone et al., 2005), and the LEM, which measures eight interaction-relevant emotions (Figure 7; Huisman \& Van Hout, 2010). Two scales that use cartoon animations are PrEmo (PrEmo1, Desmet, 2003; PrEmo 2, Figure 8, Laurans \& Desmet, 2012) used for emotional responses to product design, and Sorémo (Girard \& Johnson, 2009) intended to gauge children's emotional responses when using educational software. Note that all of these tools measure emotions, rather than moods. Two instruments are available that include some moods in their emotion sets: Russkam, a set of emoticons expressing 29 moods and emotions on three levels of intensity (Figure 9; Sanchez et al., 2006), and MAAC, developed for young children, which measures 16 moods and emotions with animated characters (Figure 10; Manassis et al., 2009). 


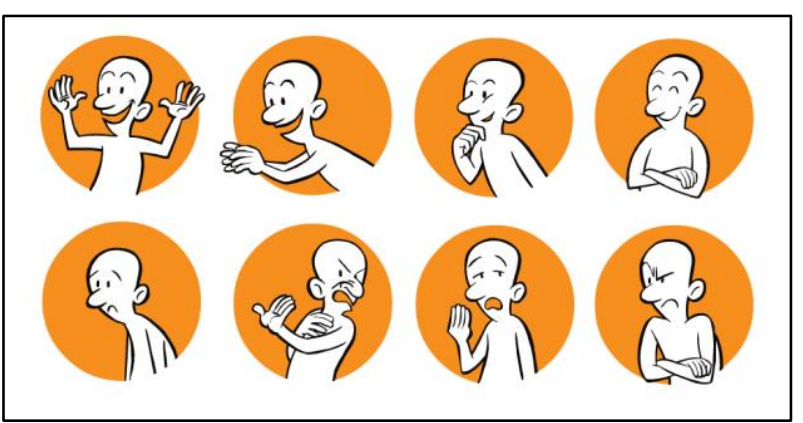

Figure 7. LEM (Huisman \& Van Hout, 2010).

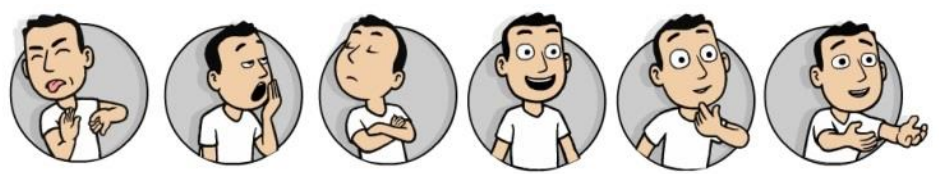

Figure 8. PrEmo2 (Laurans \& Desmet, 2012).

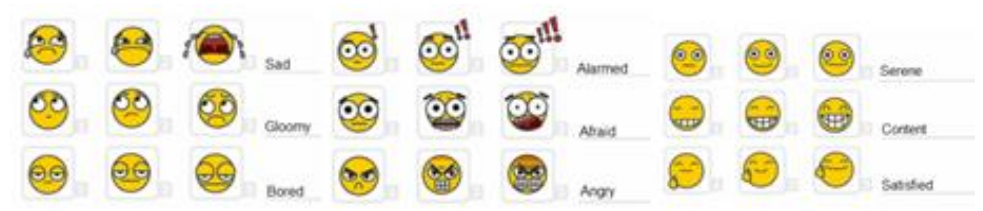

Figure 9. Russkman (fragment showing 9 of 29 affect types; Sanches et al., 2006).

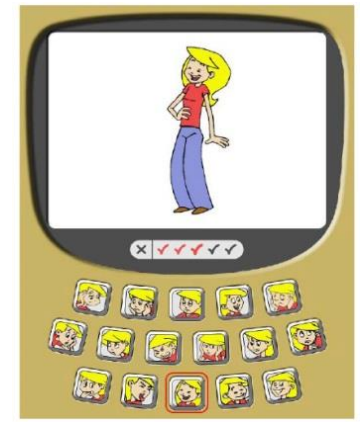

Figure 10. MAAC (Manassis et al., 2009).

Pictorial self-report methods share the goal to enable respondents to report their affective state quickly, intuitively, and accurately. An additional advantage of pictorial scales is that, when crossculturally validated, they can be used reliably across cultures, because they will not lead to translation complications (Desmet, 2003). Compared to verbal self-report scales, pictorial methods are well suited to situations in which respondents have limited time or motivation to express their affective state.

Nonetheless, like the verbal self-report, pictorial self-report is also intrusive, as respondents have to stop what it is they are doing in order to fill out the questionnaire.

\section{Mood applicability}

Several pictorial scales measure two basic dimensions of affect states, valence and arousal, while some add dominance as a third dimension. These methods, like AffectButton, are quick, easy to use, and reliable. These methods can accurately measure subtle mood changes that cannot currently be recorded with physiological or behavioural measures. Methods like PrEmo, LEM, and MAAC demonstrate that pictorial 
scales are also suitable for measuring sets of distinct affect states. To date, however, pictorial scales that specifically measure distinct mood types are not available. Most measure emotions (e.g. the GL scale); some measure sets that combine moods and emotions (e.g. Russkman), but none meets our requirement for mood measurement, which is that the method should include no states that imply a necessary relation with some object, like fascination.

\subsection{Discussion}

A wide variety of instruments are available to measure affect. Most were developed to measure emotions or general dimensions of affect (i.e. valence and arousal), and only a handful were developed to specifically measure mood states. Currently, a nuanced understanding of a person's mood state can only be obtained with the use of self-report methods. Adjective-based questionnaires are indeed available that measure nuanced profiles of distinct mood states (e.g., BRUMS and POMS-BI). For a more general understanding of mood, methods are available that measure the dimensions of pleasure, arousal, and dominance (e.g., PANAS and CMQ). While many traditional item-based self-report methods are time consuming, recently a variety of simple pictorial scales have become available for (design) research that are particularly promising, because they are quick, easy, reliable, and adaptable to the research context (e.g., PrEmo and LEM). Self-report methods, both verbal and pictorial, are not suitable, however, for the measurement of continuous and real-time mood data: respondents have to stop what they are doing to report their mood. Automatic affect recognition methods (behavioural and physiological) would likely overcome this limitation; modern methods are low-cost, non-invasive and easy to use. An undisputable benefit of these 'bodily measurements' is that they could provide insight into a user's affective state without directly relying on instantaneous, or delayed, cognitive judgment. Moreover, those that can be used without the user's knowledge (e.g., with contact sensors) minimize the risk of influencing respondents' affective states during the measurement procedure. The downside is that available methods are suitable for measuring basic arousal, or sets of basic emotions, but cannot be used to measure distinct mood states, which manifest in more subtle bodily responses and expressive behaviour.

The decision regarding what method to use depends on the purpose of the research, the participant's abilities and the context of measurement: a nuanced understanding of a momentary mood state requires self-report; the measurement of continuous data requires automatic affect recognition. It is interesting to note that methods can be combined. Picard \& Daily (2005) proposed that automatic affect recognition is best not considered as a replacement for self-report, but rather as providing additional information that may help combat some of the difficulties encountered with questionnaires. We can imagine using a wearable device to signal arousal fluctuations, and combining this with self-report to gain insight into the affective meanings of these fluctuations. Laurans (2011), for example, developed a 'selfconfrontation' method that combines continuous measurement with post-experience self-report. For this kind of application, celerity is paramount. Although all forms of self-report require some effort, the level of burden differs greatly between methods. On one side of the spectrum are questionnaires with more than 100 adjectives (e.g., MACL), and on the other are simple, smiley-based pictorial scales that demand only seconds of attention (e.g., Smileyometer). For quick and immediate self-report (as is often required in design research), simple scales are a suitable alternative. Moreover, pictorial scales have been shown to be as reliable as more conventional, adjective-based approaches to self-report. Several scales are available 
that measure either distinct emotion types or basic dimensions of affect. To date however, no pictorial scale is available that measures distinct mood types.

\section{Development and validation of Pick-A-Mood}

Pick-A-Mood is a cartoon-based pictorial self-report scale. It rapidly and intuitively enables the measurement of eight distinct mood types, and can be used in both qualitative and quantitative research settings. Pick-A-Mood consist of three sets of cartoon characters, a male, female, and robot character respectively (Figure 11). Each set includes eight expressions that portray distinct moods (Figure 12). The robot character was developed for research with children. The sets are interchangeable; choice of character can be based on the respondent population or other pragmatic considerations.
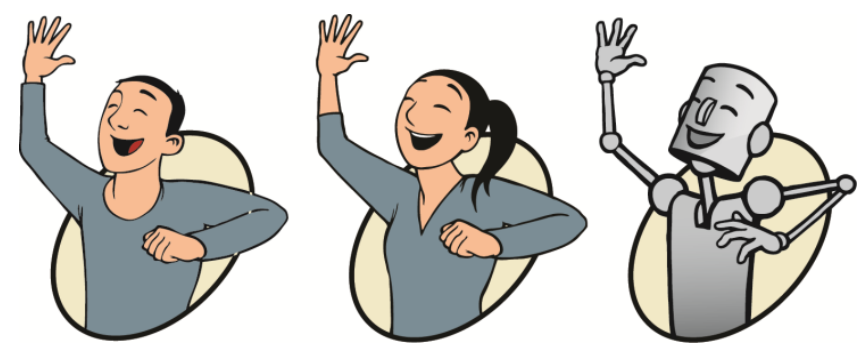

Figure 11. Three Pick-A-Mood characters, each expressing an 'Excited' mood.

The set of eight expressions can be used in print or online; respondents simply select one or more expressions which best represent(s) their mood. The illustrations and interface have been kept as simple as possible to enable versatility in application. Besides being useful to report mood, Pick-A-Mood can also be used as a mood communication tool (i.e. to enable people to express their mood on online platforms). Below, we present the three main steps to develop the tool. The first is to select mood states, the second is to develop the characters and expressions, and the third is to test the validity of the expressions.

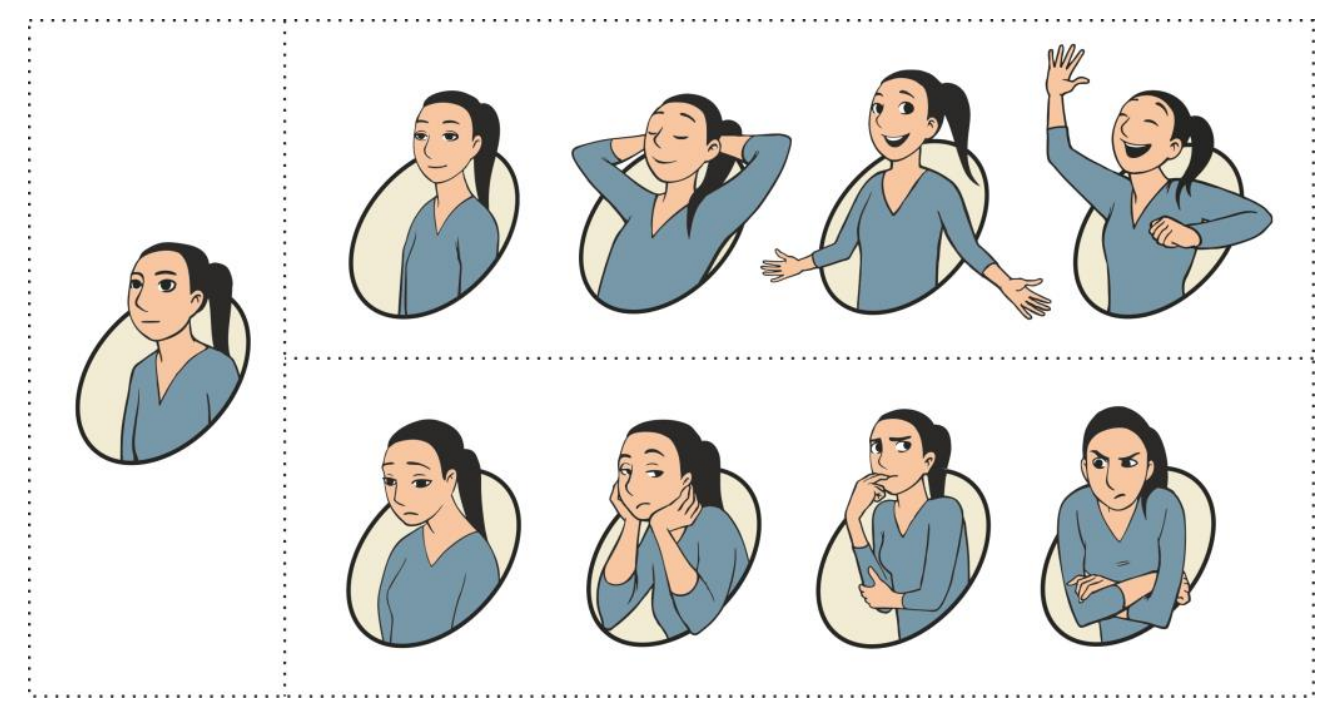

Figure 12. Pick-A-Mood female character expressing nine mood states

(Left: Neutral. Top left to right: Calm, Relaxed, Cheerful, Excited. Bottom left to right: Sad, Bored, Tense, Irritated). 


\subsection{Step 1: Mood Selection}

The first challenge was to determine the optimal level of granularity. On the one hand, the tool should enable the expression of diverse and richly-occurring moods, and on the other hand, the set of expressions needed to be small enough to allow for quick and intuitive self-report. The lowest level of granularity would be achieved with four expressions that each represents one quadrant of the valance-arousal space in Figure 2: (1) Energized-Pleasant, (2) Calm-Unpleasant, (3) Energized-Unpleasant, and (4) CalmPleasant. These four mood states have emerged consistently across diverse descriptor sets, time frames, response formats, languages, and cultures (for an overview of literature, see Watson \& Clark, 1994). Together, they account for roughly one-half to three-quarters of the common variance in mood terminology (Watson, 1988). Watson and Tellegen (1985) proposed that these basic mood categories are each composed of several correlated, yet ultimately distinguishable moods. This means that each category includes several individual moods with distinctive qualities. For example, being nervous and being irritated are both examples of 'energized-unpleasant' mood states. Thus, a higher level of granularity would probably be achieved by drawing expressions that represent some of this diversity within the four basic, higher order states. In order to understand the variety of moods within these basic states, Table 2 presents an overview of mood terminology that has been reported by mood theorists (the mood theorists in the table did not provide a rationale for the particular selection of mood states included in their analysis). For ease of comparison, we have grouped these moods under the headings of the four basic mood states.

Table 2. Typologies of mood states.

\begin{tabular}{|c|c|c|c|c|}
\hline & $\begin{array}{l}\text { ENERGIZED- } \\
\text { PLEASANT }\end{array}$ & $\begin{array}{l}\text { CALM- } \\
\text { PLEASANT }\end{array}$ & $\begin{array}{l}\text { ENERGIZED- } \\
\text { UNPLEASANT }\end{array}$ & $\begin{array}{l}\text { CALM- } \\
\text { UNPLEASANT }\end{array}$ \\
\hline $\begin{array}{l}\text { Watson \& Clark } \\
\text { (1994) }\end{array}$ & $\begin{array}{l}\text { Joviality; Attentiveness; } \\
\text { Surprise. }\end{array}$ & Serenity; Self-assurance. & Fear; Hostility; Guilt. & Sadness; Shyness; Fatigue \\
\hline $\begin{array}{l}\text { Lorr \& McNair } \\
\text { (1988) }\end{array}$ & Vigour & & $\begin{array}{l}\text { Tension-Anxiety; Anger- } \\
\text { Hostility; Confusion- } \\
\text { Bewilderment. }\end{array}$ & $\begin{array}{l}\text { Fatigue-Inertia; } \\
\text { Depression-Dejection. }\end{array}$ \\
\hline $\begin{array}{l}\text { Lorr, McNair \& } \\
\text { Fisher (1982) }\end{array}$ & $\begin{array}{l}\text { Elated; Energetic; } \\
\text { Clearheaded. }\end{array}$ & $\begin{array}{l}\text { Composed; Agreeable; } \\
\text { Confident. }\end{array}$ & $\begin{array}{l}\text { Anxious; Hostile; Unsure; } \\
\text { Confused. }\end{array}$ & Depressed; Tired. \\
\hline Russell (1980) & $\begin{array}{l}\text { Aroused; Astonished; } \\
\text { Excited; Happy; } \\
\text { Delighted. }\end{array}$ & $\begin{array}{l}\text { Pleased; Glad; Serene; } \\
\text { Content; At ease; } \\
\text { Satisfied; Relaxed; Calm; } \\
\text { Sleepy. }\end{array}$ & $\begin{array}{l}\text { Alarmed; Tense; Angry; } \\
\text { Afraid; Annoyed; } \\
\text { Distressed; Frustrated. }\end{array}$ & $\begin{array}{l}\text { Miserable; Sad; Gloomy; } \\
\text { Depressed; Bored; } \\
\text { Droopy; Tired. }\end{array}$ \\
\hline $\begin{array}{l}\text { Matthews, Jones \& } \\
\text { Chamberlain } \\
(1990)\end{array}$ & $\begin{array}{l}\text { Pleased; Cheerful; } \\
\text { Optimistic; Happy; Active; } \\
\text { Energetic; Industrious; } \\
\text { Alert; Fortunate; } \\
\text { Vigorous; Bright. }\end{array}$ & $\begin{array}{l}\text { Contented; Satisfied; } \\
\text { Calm; Restful; Relaxed; } \\
\text { Unconcerned; Composed; } \\
\text { Self-controlled; Peaceful; } \\
\text { Comfortable; Placid. }\end{array}$ & $\begin{array}{l}\text { Impatient; Annoyed; } \\
\text { Angry; Irritated; Grouchy; } \\
\text { Stirred up; Fearful; } \\
\text { Anxious; Jittery; Tense; } \\
\text { Stressed; Nervous. }\end{array}$ & $\begin{array}{l}\text { Low-spirited; Dissatisfied; } \\
\text { Gloomy; Depressed; Sad; } \\
\text { Sorry; Idle; Sleepy; Dull; } \\
\text { Unenterprising; Sluggish; } \\
\text { Tired. }\end{array}$ \\
\hline
\end{tabular}

Note that it is debatable whether all these adjectives in fact refer to moods. For example, shyness is a personality trait, and anger and surprise are emotions. Nonetheless, Table 2 illustrates the range of moods that can be observed within each of the four basic mood states. For example, the basic mood state 'energized-unpleasant' represents Nervousness-Tension-Anxiety, but also Irritated-Hostile-Annoyed. Calm-unpleasant represents Sad-Depressed-Gloomy, but also Fatigue-Inertia-Boredom.

To enable mood measurement that is more nuanced than what would be the case using only the four basic mood states, and, at the same time, keep the scale simple and quick to administer, we decided to 
include eight distinct moods: two for each of the four mood categories (Figure 13). In this way, we capture the four main mood categories, and add nuance by distinguishing between two moods within these categories. These were selected to represent the main mood differentiations found in the mood typologies in Table 2. We used the third dimension of affect, 'dominance' in our selection procedure. This affective dimension represents the degree to which the person who is experiencing it has a sense of power or control (Mehrabian, 1996). Take, for instance, the moods 'irritated' and 'nervous'. They are both unpleasant-activated moods, but irritated is dominant (the individual has a sense of power), and nervous is not (the individual feels powerless) (see Lazarus, 1991). We used this dimension to select two further moods from each category.

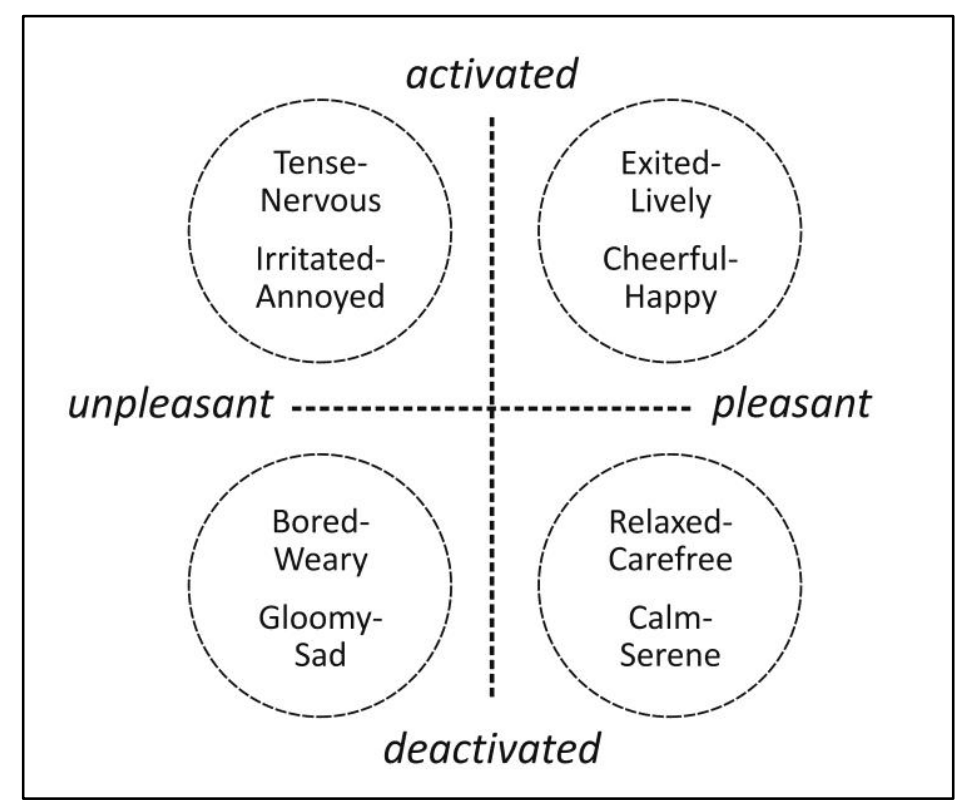

Figure 13. Eight moods measured by Pick-A-Mood, grouped into four mood categories (the four mood categories are drawn from Watson and Tellegen, 1985).

\subsection{Step 2: Character and Expression Development}

A professional cartoonist developed three different characters to enable freedom of application. After several design iterations, a neutral-aged male, a neutral-aged female, and a non-human character (teapot) were selected (Figure 14).
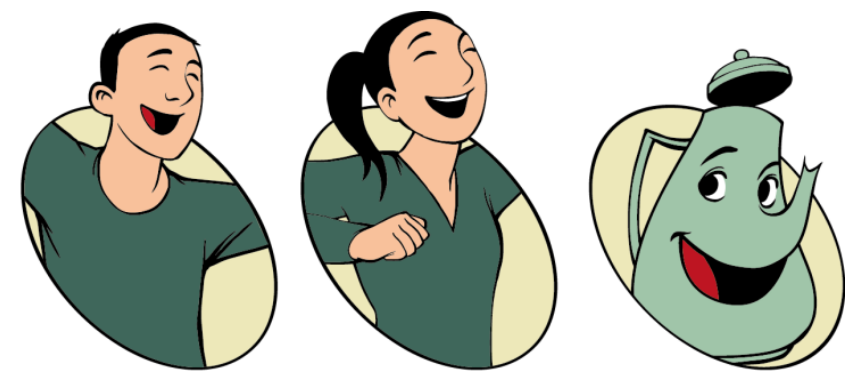

Figure 14. Three initial Pick-A-Mood characters (expressing the Excited-Lively mood). 
The cartoonist created nine expressions for each character: one for each mood and an additional expression that represents a 'neutral' mood. The design and validation of these initial expressions was reported in a previous publication (Desmet et al., 2012). Although the results of the validation study indicated that most expressions were recognized unambiguously, indicating that people are capable of recognizing and distinguishing between these mood expressions, five potential improvements were identified. First, the teapot expressions were found to be relatively difficult to recognize. Second, the interpretations of Tense and Irritated partly overlapped. The same applied to Neutral, Calm and Relaxed. Third, because interpretations were influenced by minor differences in the expressions between the characters, comparisons of mood-reports across the three characters was hindered. Fourth, the green colour of the characters' clothing was experienced as non-neutral (i.e. green can be associated with positive). Fifth, the expressions' passe-partout hid the arms or hands in some expressions (see Figure 14), which reduced the communicative quality of these expressions. In several design and testing iterations, new drawings were created to improve on the above-stated shortcomings. After some design explorations, it was decided to replace the teapot with a robot character, because a robot with arms and legs better resembles the human anatomy, thereby enabling more accurate expressions. The green colour was changed to blue, the expressions between characters were made consistent, some expressions were made more explicit so as to be more easily discriminated, and the passe-partout hides no part of the arms or hands (see Figures 11 and 12).

\subsection{Step 3: Character Validation}

An evaluation study was designed to test if the eight expressions (plus the neutral expression) portray differentiated mood states, representing all four basic mood categories, and if people correctly recognize the intended mood states. In total, 191 people participated, recruited through informal social networks, including 31 different nationalities (of which 52\% were Dutch), including people from various countries in Europe, Asia, Australia, South-America, Canada, and the Middle-East. Age ranged between 13 and 76 (mean $=34,9 ; \mathrm{SD}=13,0)$, and $47 \%$ were female.

\section{Procedure}

Participants filled out a web-based questionnaire (in Dutch or English; N-Dutch = 100; N-English = 91). Each participant was randomly assigned to respond to one of the three characters, which could be either the version with the same gender as the respondent or the robot version $(\mathrm{N}$-male $=66 ; \mathrm{N}$-female $=61 ; \mathrm{N}$ robot $=64$ ). Expression order presentation was randomized. The procedure consisted of three stages: in

Stage 1, participants generated a text-label for each of the nine expressions. This was an open question, without the option to select from a list of pre-determined labels. In Stage 2, participants were asked to select a label for each expression from a set of nine predefined labels: excited, cheerful, relaxed, calm, bored, sad, irritated, tense, and neutral. In Stage 3, participants rated each expression on the basic affect dimensions of valence and arousal with bipolar scales (unpleasant-pleasant and calm-energized). Based on the recommendations of McKelvie (1978) it was decided to use five-point scales, balancing between having enough points of discrimination without having to too many response options.

\section{$\underline{\text { Results }}$}

Table 3 summarizes the findings for the labelling task. The second column gives an overview of the results of the free labelling task (Dutch labels were translated with the Van Dale dictionary (2009) software). The 
number between brackets represents the number of respondents that reported that word; only words with frequency of two or higher are included in the overview. The third column shows the four labels most often selected, with the percentage of respondents who provided this label. The fourth column shows the labels that respondents selected (in the second stage of the questionnaire) from a fixed set of labels. Labels with percentage of lower than 10 are not included in the table.

Table 3. Reported and selected labels for all mood expressions ( $N=191)$.

\begin{tabular}{|c|c|c|c|}
\hline Expression & $\begin{array}{l}\text { Stage 1: } \\
\text { Open labelling (frequencies) }\end{array}$ & $\begin{array}{l}\text { Stage 2: } \\
\text { Open labelling } \\
\text { (percentages) }\end{array}$ & $\begin{array}{l}\text { Stage 3: } \\
\text { Forced labelling } \\
\text { (percentages) }\end{array}$ \\
\hline EXCITED & $\begin{array}{l}\text { Joyful (28); Happy (27); Excited (25); Exuberant (23); Cheerful } \\
\text { (17); Joyous (8); Enthusiastic (5); Jolly (5); Laughing (5); Very } \\
\text { happy (5); Overjoyed (4); Ecstatic (3); Elated (3). }\end{array}$ & $\begin{array}{l}\text { Joyful }(17 \%) \\
\text { Happy }(17 \%) \\
\text { Excited }(15 \%) \\
\text { Exuberant }(14 \%) \\
\end{array}$ & $\begin{array}{l}\text { Excited }(78 \%) \\
\text { Cheerful }(20 \%)\end{array}$ \\
\hline CHEERFUL & $\begin{array}{l}\text { Happy (43); Joyful (42); Cheerful (19); Relieved (11); } \\
\text { Welcoming (5); Open (5); Satisfied (4); Surprised (3); Proud } \\
\text { (3). }\end{array}$ & $\begin{array}{l}\text { Happy }(30 \%) \\
\text { Joyful }(29 \%) \\
\text { Cheerful }(13 \%) \\
\text { Relieved }(8 \%)\end{array}$ & $\begin{array}{l}\text { Cheerful }(82 \%) \\
\text { Excited }(14 \%)\end{array}$ \\
\hline RELAXED & Relaxed (136); Satisfied (13); Content (10); Enjoying (3). & $\begin{array}{l}\text { Relaxed (81\%) } \\
\text { Satisfied (8\%) } \\
\text { Content }(6 \%) \\
\text { Enjoying }(2 \%) \\
\end{array}$ & Relaxed (95\%) \\
\hline CALM & $\begin{array}{l}\text { Neutral (75); Dreamy (14); Satisfied (6); Calm (5); Content (4); } \\
\text { Bored (3); Waiting (3). }\end{array}$ & $\begin{array}{l}\text { Neutral (59\%) } \\
\text { Dreamy (11\%) } \\
\text { Satisfied (5\%) } \\
\text { Calm (4\%) }\end{array}$ & $\begin{array}{l}\text { Calm }(40 \%) \\
\text { Neutral }(39 \%) \\
\text { Relaxed }(13 \%)\end{array}$ \\
\hline SAD & $\begin{array}{l}\text { Sad (78); Depressed (15); Gloomy (13); Disappointed (12); } \\
\text { Tired (8); Dispirited (7); Glum (6); Upset (4); Disheartened } \\
\text { (4); Sorrowful (3); Defeated (3). }\end{array}$ & $\begin{array}{l}\text { Sad }(50 \%) \\
\text { Depressed (10\%) } \\
\text { Gloomy (9\%) } \\
\text { Disappointed (8\%) }\end{array}$ & Sad (96\%) \\
\hline BORED & $\begin{array}{l}\text { Bored (83); Disinterested (7); Pensive (6); Tired (6); Sad (5); } \\
\text { Disappointed (5); Dreamy (4); Thoughtful (3); Melancholic (3). }\end{array}$ & $\begin{array}{l}\text { Bored }(64 \%) \\
\text { Disinterested (5\%) } \\
\text { Pensive }(5 \%) \\
\text { Tired }(5 \%)\end{array}$ & $\begin{array}{l}\text { Bored }(77 \%) \\
\text { Sad }(10 \%)\end{array}$ \\
\hline IRRITATED & $\begin{array}{l}\text { Angry (82); Irritated (17); Suspicious (9); Grumpy (6); } \\
\text { Frustrated (4); Annoyed (4); Dissatisfied (3); Disgusted (3). }\end{array}$ & $\begin{array}{l}\text { Angry (55\%) } \\
\text { Irritated (12\%) } \\
\text { Suspicious }(6 \%) \\
\text { Grumpy }(4 \%) \\
\end{array}$ & $\begin{array}{l}\text { Irritated }(89 \%) \\
\text { Tense }(11 \%)\end{array}$ \\
\hline TENSE & $\begin{array}{l}\text { Nervous (19); Pensive (18); Worried (15); Thoughtful (14); } \\
\text { Hesitant (12); Doubtful (11); Preoccupied (9); Confused (7); } \\
\text { Suspicious (6); Uncertain (5); Cautious (5); Anxious (5); } \\
\text { Despair (4); Curious (4); Afraid (4); Scared (3); Pondering (3); } \\
\text { Insecure (3). }\end{array}$ & $\begin{array}{l}\text { Nervous }(12 \%) \\
\text { Pensive }(11 \%) \\
\text { Worried }(9 \%) \\
\text { Thoughtful }(9 \%)\end{array}$ & Tense $(76 \%)$ \\
\hline NEUTRAL & $\begin{array}{l}\text { Neutral (44); Astonished (16); Surprised (8); Serious (5); } \\
\text { Attentive (5); Amazed (4); Thoughtful (3); Shocked (3); } \\
\text { Pensive (3); Hypnotized (3); Concentrated (3); Alert (3). }\end{array}$ & $\begin{array}{l}\text { Neutral (42\%) } \\
\text { Astonished (15\%) } \\
\text { Surprised (8\%) } \\
\text { Serious (5\%) }\end{array}$ & $\begin{array}{l}\text { Neutral }(59 \%) \\
\text { Tense }(18 \%) \\
\text { Calm }(11 \%)\end{array}$ \\
\hline
\end{tabular}

The forced-labelling percentages indicate that $75 \%$ to $96 \%$ of the participants selected the correct label for seven expressions: Excited , Cheerful, Relaxed, Bored, Sad, Irritated, and Tense. Calm and Neutral were interpreted as being similar: Calm is misinterpreted by $39 \%$ of the respondents as being neutral (and by $13 \%$ as relaxed), and Neutral is misinterpreted by $11 \%$ as calm. Moreover, Neutral is also misinterpreted (by $18 \%$ ) as tense. 
Valence and arousal ratings are shown in Table 4 and Figure 15. Multivariate ANOVA's with valence and arousal as dependent variables and character as the independent $(\mathrm{F}(2,188))$ did not find significant differences, indicating that rating results were similar for the three characters. Likewise, no significant gender effect was found with multivariate ANOVA's with gender as independent and valance and arousal as dependent variables $(F(1,189)$. To test if all mood quadrants were properly represented, a t-test (df 190) was done for each expression, with the scale mid-point as the test value. The test found significant ( $p$ $<.001$ ) differences for all expressions on both pleasantness and arousal (see Table 4): Excited and Cheerful are high valence and high arousal (energized-pleasant); Relaxed and Calm are high valence and low arousal (calm-pleasant); Bored and Sad are low valence and low arousal (calm-unpleasant); Irritated and Tense are low valence and high arousal (energized-unpleasant). For the Neutral expression, the difference for arousal was significant (lower than midpoint) but not for valence.

Table 4.Valence and arousal ratings of Expressions and comparison with scale midpoint ( $N=191)$.

\begin{tabular}{lcccccc}
\multirow{2}{*}{ Expression } & \multicolumn{3}{c}{ Valence } & \multicolumn{4}{c}{ Arousal } \\
\cline { 2 - 8 } EXCITED & Mean & SD & $\mathrm{t}(190)$ & Mean & SD & $\mathrm{t}(190)$ \\
\hline CHEERFUL & 4.92 & .30 & $89.43^{*}$ & 4.68 & .79 & $29.40^{*}$ \\
\hline RELAXED & 4.55 & .57 & $37.71^{*}$ & 3.80 & .87 & $12.79^{*}$ \\
\hline CALM & 4.47 & .70 & $28.88^{*}$ & 1.36 & .80 & $-28.49^{*}$ \\
\hline BORED & 3.38 & .72 & $7.22^{*}$ & 2.09 & .92 & $-13.74^{*}$ \\
\hline SAD & 2.42 & .81 & $-9.83^{*}$ & 1.90 & .83 & $-18.29^{*}$ \\
\hline IRRITATED & 1.61 & .70 & $-27.36^{*}$ & 1.87 & .99 & $-15.80^{*}$ \\
\hline TENSE & 1.62 & .61 & $-31.22^{*}$ & 4.03 & .78 & $18.26^{*}$ \\
\hline NEUTRAL & 2.54 & .72 & $-8.80^{*}$ & 3.26 & .96 & $3.77^{*}$ \\
\hline \multicolumn{2}{c}{2.88} & .61 & -2.64 & 2.59 & .96 & $-5.97^{*}$ \\
\hline
\end{tabular}

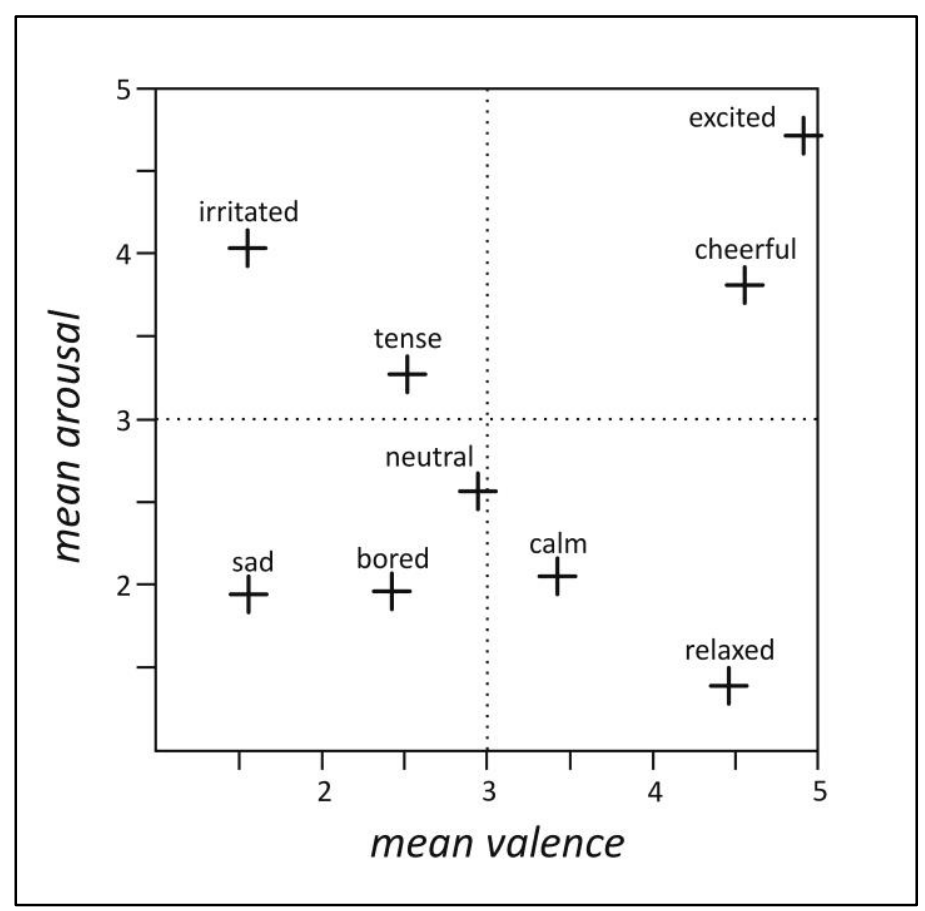

Figure 15. Valence and arousal ratings of Pick-A-Mood expressions. 
To test if the two expressions within each category differentiate in terms of valence and arousal, Multivariate ANOVA's were performed with valence and arousal as the dependent variables, and the expression as the fixed factor, see Table 5.

\begin{tabular}{rrrr}
\multicolumn{4}{c}{ Table 5. Comparison of Expression means for Valence and Arousal. } \\
\hline Expression A & \multirow{2}{*}{ Expression B } & $\begin{array}{c}\text { Valence } \\
\mathrm{F}(1,380)\end{array}$ & $\begin{array}{r}\text { Arousal } \\
\mathrm{F}(1,380)\end{array}$ \\
\hline IRRITATED & TENSE & $180.67^{*}$ & $73.94^{*}$ \\
\hline EXCITED & CHEERFUL & $62.54^{*}$ & $106.58^{*}$ \\
\hline SAD & BORED & $109.64^{*}$ & .11 \\
\hline RELAXED & CALM & $223.70^{*}$ & $68.75^{*}$ \\
\hline NEUTRAL & CALM & $53.10^{*}$ & $26.90^{*}$ \\
\hline NEUTRAL & TENSE & $24.77^{*}$ & $47.40^{*}$ \\
\hline NEUTRAL & BORED & $38.64^{*}$ & $55.89^{*}$ \\
\hline & $*$ indicates significance at $p<.01$ &
\end{tabular}

Table 5 indicates that Sad and Bored differed only in terms of valence: Sad was perceived as more unpleasant than Bored. All other pairs differed both in valance and arousal: Excited was seen as more pleasant and more energetic than Cheerful; Relaxed as more pleasant and less energetic than Calm; Irritated as less pleasant and more energetic than Tense. The last three rows of Table 5 show differences between Neutral and the three most similar expressions, indicating that Neutral differed both in terms of valance and arousal with all three other expressions.

\section{Conclusions and discussion}

The validation results indicate that the eight mood expressions portray a diverse pallet of moods, representing all four basic mood categories. Moreover, the two mood-expressions within each basic category represent mood states that differ in terms of type, valence and/or arousal, adding nuance to the set. When provided with labels, respondents were able to select the correct label for the various expressions. The labelling did indicate some overlap between expressions within the basic mood categories. This is in line however with what has been found in other affect studies (e.g. Russell, 1980). For example, the labelling for Excited and Cheerful showed some overlap, and the same applies to the labelling for Irritated and Tense. However, the valence and arousal data indicated significant differences between the mood expressions within categories: Excited is perceived as more energetic and more pleasant than Cheerful, and Irritated is perceived as less energetic and more unpleasant than Tense, indicating that these expressions enrich the level of nuance of the Pick-A-Mood character set. Note that positive affect is often found to differentiate less than negative affect (e.g. Russell, 1980), which is also observed in the current study. One could argue that using either Excited or Cheerful would be sufficient for a differentiated measurement, but we advocate for using both because of the advantages of having a balanced set. Affect measurement instruments (for both emotion and mood) tend to be biased towards the negative (i.e. including more negative than positive items), which may be appropriate for the typical, clinical applications for which they may have been developed, but is unwanted for application in design research (see Desmet, 2003).

The results indicate that the interpretation of the Neutral expression was ambiguous. This expression was included in the Pick-A-Mood set because we envisioned it might be useful in measurement 
situations to serve a 'baseline mood' reference. In the forced labelling, almost 20 per cent labelled this expression as tense, and in the open labelling, 15 per cent used the word 'astonishment.' One explanation could be that the drawing is incorrect. However, Figure 15 indicates that respondents did interpret Neutral correctly when asked to rate pleasantness and arousal. An alternative explanation is that the results may have been an effect of the questionnaire: because respondents were instructed to describe the mood, it might not have been apparent that they could also select 'neutral'. In addition, a neutral mood may not even be part of our affective repertoire. The circumplex model of affect (Russell, 1980), for example, does not include neutral: we are always in some mood. Given the findings, it is advisable to take caution when using the neutral expression in a measurement. We propose to provide some indication on how this expression should be interpreted, for example with the graphical layout of the set (see e.g., Figure 12). Apart from Neutral, the Calm expression scored weakest in the labelling task. The number of respondents who selected the label calm is equal to the number of respondents who selected the label neutral. The expressions are indeed very similar (see Figure 12). However, in the study, Calm was seen as more pleasant than Neutral, as is shown in Table 5, indicating that the character adds granularity to the set.

\section{General Discussion}

In an average day, the bulk of our waking life is non-emotional. And yet, our waking consciousness is experienced as a continuous stream of affect. This is because even though emotions occur only infrequently, people are always in some mood (Watson \& Clark, 1994). Moods represent the positive and negative frames of mind that subtly influence our responses to all the events we encounter (Kelley \& Hoffman, 1997; Martin \& Clore, 2013). Unlike emotions, moods are not directed toward specific targets, but instead have a broad influence on one's perceptions, judgments, and behaviour (Morris, 1989). To better grasp how users adopt innovative immersive technology over the long term, it is crucial to understand how this technology affects users' moods, and how these moods affect user-technology interactions. Eventually, this could contribute to designers' ability to create technology, products, and services that are responsive to users' subjective well-being. This is of interest for designers who aim to design products and systems that contribute to human welfare (either by diminishing welfare threats, or by stimulating welfare opportunities; see, Desmet \& Pohlmeyer, 2013, and Desmet, 2015). Given the fact that moods are by nature a more stable information source than emotions for monitoring people's wellbeing (Csikszentmihalyi \& Hunter, 2003), mood measurement can play a relevant role in these kinds of efforts in a variety of design domains. For example, designers can use information on how design choices affect moods to improve their designs of waiting rooms (e.g. airports, hospitals, public transport, etcetera) or other functional rooms (e.g. lecture halls, prisons, schools, office spaces, etcetera). Given the current developments in ambient technology, one can also think of intelligent atmosphere control systems that automatically adapt their behaviour according to the mood of the user (Vastenburg et al., 2007). An interesting opportunity for future developments is to explore how simple self-report methods can be combined with automatic affect recognition systems (e.g. wearable devices) to identify longitudinal 'mood patterns.' The ability to log such patterns can be of use for the rapidly evolving domain of persuasive technologies, which aim to support people in adopting new practices. Identifying mood patterns can potentially enable such systems to adjust to the "mood of the moment." 
In this paper we proposed that, in contrast to what is often assumed, methods that have been developed to measure emotions are not always suitable to also measure moods. At the same time, a wide pallet of methods is available for mood measurement, and different methods are suitable for different research question and study designs. Each type of method has both strengths and weaknesses. Behavioural and physiological methods are suitable for continuous measurement. These methods measure basic emotions or general affect dimensions, like arousal and valence; self-report methods are better suitable for measuring nuanced mood profiles. However, filling out verbal questionnaires can be demanding for the respondent and requires cognitive processing which may distort the original feelings. These limitations can be overcome with simple verbal or pictorial self-report scales. However, both alternatives have drawbacks: in the case of verbal scales, terms can be interpreted differently (or even incorrectly) across cultures, and in the case of pictorial scales, item selection is less flexible because adding new items involves a time-consuming development requiring specialist drawing skills. Pick-AMood, presented in this paper, contributes to the repertoire of methods by measuring a set of eight distinct mood states. It is a cartoon-based pictorial instrument for reporting and expressing moods exclusively. The use of cartoon characters enables people to unambiguously and visually express or report their mood in a rich and expeditious manner. Pick-A-Mood is available in both paper and electronic versions under a Creative Commons license, free-of-charge for non-commercial use (http://studiolab.ide.tudelft.nl/diopd/library/tools/pic-a-mood/); the instrument has been made freely available to anyone seeking to collect rich data, sample experiences, create remote awareness, and enable self-expression in a wide range of design-related applications.

Future developments of Pick-A-Mood will focus on the development of interfaces that support various online and offline applications, and on exploring how the self-report characters can be combined with sensor-based measurements. Another direction will be to develop additional sets to suit particular user demographics. For example, Carolina Sandoval of the Universidad Católica de la Santísima Concepción (Chile) is in the process of developing characters that focus on senior respondents (Figure 16).

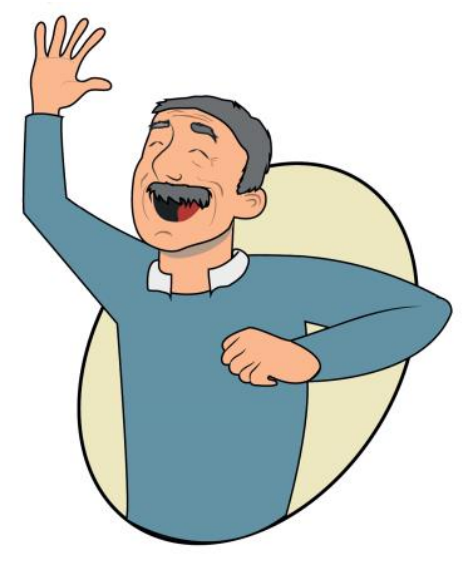

Figure 16. Pick-A-Mood for senior respondents

Recently, a manual has been published that provides guidelines on how to use Pick-A-Mood (Desmet et al., 2016). This manual, which is now available with the tool, was developed on the basis of feedback from 20 Pick-A-Mood users (who were invited to provide feedback with a separate 
questionnaire). These researchers used the tool to measure moods in a variety of populations, including managers, children, teenagers, students, patients recovering from medical treatments, and people with disabilities. Mood was measured in a variety of contexts, such as when watching advertisements, attending lectures, reading, and in relation to sleep quality or hurtful memories. Several studies have been published, providing further guidance and inspiration for application possibilities. Hilbolling et al. (2012) used the characters in an interview study to assess mood variations of delayed international travellers at Amsterdam airport. In another study, Hilbolling et al. (2011) used the Pick-A-Mood set in a study of user mood during the use of GPS car navigation devices. Pascual et al. (2014a) measured the moods of people with a hearing impairment when using websites, and Pascual, et al. (2014b) did the same with a population that had low-vision abilities. Pasman et al. (2013) used Pick-A-Mood to measure mood of design students during the realisation of their design projects. Villa et al. (2014) used Pick-A-Mood as part of a pre-questionnaire to check mood before respondents participated in their study measuring the quality of experience in the context of adaptive video streaming. Besides mood measurement and interpretation, the set has also been used as a means for mood communication. Vastenburg and Romero (2011) reported an application in which the Pick-A-Mood set was used for expressing moods in a social awareness communication device. The system was used to improve communication between seniors in need of care and their family caregivers. Jimenez et al. $(2011 ; 2013 ; 2014)$ used Pick-A-Mood in a contextaware system that monitors patients' recovery experiences after being discharged from the hospital, to reduce the general lack of information regarding their feelings during recovery. The system uses Pick-AMood for mood expression in order to enable it to support the day-to-day recovery process of elderly patients, including meeting physical and emotional support requirements. Alberts et al. (2013) explored how the characters can be used to enable seniors to express their mood in digital communications, and Hupont et al. (2014) explored possible applications of Pick-A-Mood to express mood in a crowdsourcing context.

The ability to read and to express moods facilitates successful social interactions. Because this ability is often impeded when using technology-supported remote social interaction platforms (Sanchez et al., 2006), pictorial scales like Pick-A-Mood can be integrated into communication tools to enable social communities to share experiences. For example, a group of friends that use social networks to share locations could use a pictorial scale to express their mood at these locations. Similarly, pictorial scales could be part of an engaging communication tool in senior-care systems. Mood-characters can be used to invite seniors to provide richer information about their well-being (Vastenburg \& Romero, 2011). Moodcharacters could further be integrated into context-aware experience sampling tools. In their Mobile Heart Health Project, Morris and Guilak (2009) tested how ESG sensor data linked to mood self-reports can be used as input driving suggestions for 'mobile therapies' to control stress. Mood-characters can be used to simplify the mood self-report procedures in such systems. A similar system could be used when evaluating a prototype in the field: participants can be asked to annotate their user-product interactions with moods. Another application possibility is to support people's active involvement in improving their quality of life using so-called Personal Informatics Systems (Li et al., 2011). These systems use of selftracking devices and applications to collect the impact of people's actions, for them to interpret, reflect on, and act upon. Self-reflection of one's performance and mood over longer periods of time provides individuals with an integral view of their own actions to answer questions such as: how does my mood generally change during working hours? or how is my mood influenced by sports or light exposure? These 
kinds of applications can ideally enable people to actively balance their mood and stimulate general mood awareness, which can contribute to long-term well-being (see Diener \& Sandvik (1994) for a discussion on mood and well-being).

\section{ACKNOWLEDGMENTS}

This research was supported by the Innovation-Oriented Research Program 'Integral Product Creation and Realization (IOP IPCR)' of the Netherlands Ministry of Economic Affairs, and the MAGW VIDI grant number 452-10-011 of The Netherlands Organization for Scientific Research (N.W.O.) awarded to P.M.A. Desmet. Lois van Baarle (initial version) and Peter Wassink (final version) created the Pick-A-Mood characters and expressions. We thank Jianne Whelton for copy editing the manuscript and Boudewijn Boon for his contribution to the literature review and Pick-A-Mood user evaluation study, and we express our gratitude to all authors who kindly granted us permission to reprint their images (Figures 1, 4, 5, 6, 7, 8,9 , and 10).

\section{REFERENCES}

Alonso, M. B., Keyson, D. V., \& Hummels, C. (2008). Squeeze, rock, and roll; can tangible interaction with affective products support stress reduction? In Proceedings of the 2nd International Conference on Tangible and Embedded Interaction (pp. 105-108). New York: ACM.

Arnold, M. J., \& Reynolds, K. E. (2009). Affect and retail shopping behavior: Understanding the role of mood regulation and regulatory focus. Journal of Retailing, 85(3), 308-320.

Arroyo, I., Cooper, D. G., Burleson, W., Woolf, B. P., Muldner, K., \& Christopherson, R. (2009). Emotion sensors go to school. In Proceedings of the 14th Conference on Artificial Intelligence in Education (pp. 17-24). Amsterdam: IOS Press.

Asthana, A., Saragih, J., Wagner, M., \& Goecke, R. (2009). Evaluating AAM fitting methods for facial expression recognition. In Proceedings of the 2009 International Conference on Affective Computing and Intelligent Interaction (pp. 1-8). Alamitos: IEEE.

Bailenson, J. N., Pontikakis, E. D., Mauss, I. B., Gross, J. J., Jabon, M. E., Hutcherson, C. A., ... \& John, O. (2008). Real-time classification of evoked emotions using facial feature tracking and physiological responses. International Journal of Human-Computer Studies, 66(5), 303-317.

Bänziger, T., Patel, S., \& Scherer, K. R. (2014). The role of perceived voice and speech characteristics in vocal emotion communication. Journal of Nonverbal behavior, 38(1), 31-52.

Barrett, L. F. and Russell, J. A. (1999). Structure of current affect. Current Directions in Psychological Science, 8, 10-14.

Beedie, C. J., Terry, P.C., \& Lane, A. M. (2005). Distinctions between emotion and mood. Cognition \& Emotion, 119(6), 847-878.

Bianchi-Berthouze, N., \& Lisetti, C. (2002). Modeling multimodal expression of user's affective subjective experience. User Modeling and User-Adapted Interaction, 12, 49-84.

Bradley, M. M., \& Lang, P. J. (1994). Measuring emotion: the self-assessment manikin and the semantic differential. Journal of Experimental Psychiatry \& Behavior Therapy 25(1), 49-59.

Brick, T., Hunter, M., \& Cohn, J. (2009). Get the FACS fast: automated FACS face analysis benefits from the addition of velocity. In Proceedings of the 2009 International Conference on Affective Computing and Intelligent Interaction (pp. 1-7). Alamitos: IEEE.

Broekens, J., \& Brinkman, W. P. (2013). AffectButton: A method for reliable and valid affective self-report. International Journal of Human-Computer Studies, 71(6), 641-667. 
Cai H., \& Lin, Y. (2007). An experiment to non-intrusively collect physiological parameters towards driver state detection. In Proceedings of the 2007 SAE World Congress, Detroit, MI, USA, April 16-19 2007.

Calvo, R.A., D’Mello, S. (2010). Affect detection: An interdisciplinary review of models, methods, and their applications. IEEE Transactions on Affective Computing, 1(1), 18-37.

Castellano, G., Mortillaro, M., Camurri, A., Volpe, G., \& Scherer, K. (2008). Automated analysis of body movement in emotionally expressive piano performances. Music Perception, 26, 103- 119.

Chanel, G., Rebetez, C., Bétrancourt, M., \& Pun, T. (2011). Emotion assessment from physiological signals for adaptation of game difficulty. IEEE Transactions on Systems, Man and Cybernetics, Part A: Systems and Humans, 41(6), 1052-1063.

Church, K., Hoggan, E., \& Oliver, N. (2010). A study of mobile mood awareness and communication through MobiMood. In Proceedings of the 6th Nordic Conference on Human-Computer Interaction: Extending Boundaries (pp. 128137). New York: ACM.

Coan, J. A., \& Allen, J. J. (2007). Handbook of emotion elicitation and assessment. Oxford: Oxford University Press.

Cohn, J. F., \& De la Torre, F. (2014). Automated face analysis for affective computing. In R.A. Calvo, S D'Mello, J. Gratch, \& A. Kappas (Eds.), The Oxford handbook of affective computing (pp. 131-150). Oxford: Oxford University Press.

Cowie, R., Douglas-Cowie, E., Savvidou, S., McMahon, E., Sawey, M., \& Schröder, M. (2000). 'FEELTRACE': An instrument for recording perceived emotion in real time. Paper presented at Speech and Emotion: Proceedings of the ISCA workshop, Newcastle, United Kingdom (pp. 19-24).

Csikszentmihalyi, M., \& Hunter, J. (2003) Happiness in everyday life: the uses of experience sampling. Journal of Happiness Studies, 4, 185-2003.

Curren, S. L., Andrykowski, M. A., \& Studts, J. L. (1995). Short form of the Profile of Mood States (POMS-SF): Psychometric information. Psychological Assessment, 7, 80-83.

Davidson, R. J. (1994). On emotion, mood, and related affective constructs. In P. Ekman \& R. J. Davidson (Eds.), The nature of emotion, fundamental questions (pp. 51-55). Oxford: Oxford University press.

Davis, F., Roseway, A., Carroll, E., \& Czerwinski, M. (2013). Actuating mood: design of the textile mirror. In Proceedings of the 7th International Conference on Tangible, Embedded and Embodied Interaction (pp. 99-106). New York: ACM.

Desmet, P. M. A. (2002). Designing emotions. Unpublished doctoral dissertation. Delft: Delft University of Technology.

Desmet, P. M. A. (2003). Measuring emotion; development and application of an instrument to measure emotional responses to products. In M. A. Blythe, A. F. Monk, K. Overbeeke, \& P. C. Wright (Eds.), Funology: from usability to enjoyment (pp. 111-123). Dordrecht: Kluwer Academic Publishers.

Desmet, P. M. A. (2008). Product Emotion. In: P. Hekkert, \& H. N. J. Schifferstein (Eds.), Product Experience (pp. 379397). Amsterdam: Elsevier.

Desmet, P. M. A. (2011). Design for Happiness; four ingredients for designing meaningful activities. In N. F. M. Roozenburg \& P. J. Stappers (Eds.), Proceedings of the IASDR2011, the Fourth World Conference on Design Research [CD-ROM], 31 October - 4 November, Delft. Delft: Delft University of Technology.

Desmet, P. M. A. (2015). Design for mood: Twenty activity-based opportunities to design for mood regulation. Manuscript submitted for publication. International Journal of Design, 9(2), 1-19.

Desmet, P. M. A., \& Hassenzahl, M. (2012). Towards happiness: Possibility-driven design. In M. Zacarias \& J. V. Oliveira de (Eds.), Human-computer interaction: The agency perspective (pp. 3-27). New York: Springer.

Desmet, P. M. A., Vastenburg, M. H., \& Romero, N. (2016). Pick-A-Mood manual. Delft: Delft University of Technology.

Desmet, P. M. A., Vastenburg, M. H., Van Bel, D., \& Romero Herrera, N. (2012). Pick-A-Mood; development and application of a pictorial mood-reporting instrument. In J. Brassett, P. Hekkert, G. Ludden, M. Malpass, \& J., 
McDonnell (Eds.), Proceedings of the 8th International Design and Emotion Conference [CD-ROM], London, UK, 11-14 September 2012. London, UK: Central Saint Martin College of Art \& Design.

Desmet, P. M., \& Pohlmeyer, A. E. (2013). Positive design: An introduction to design for subjective well-being. International Journal of Design, 7(3), 2013.

Desmet, P., Overbeeke, K., \& Tax, S. (2001). Designing products with added emotional value: Development and application of an approach for research through design. The design journal, 4(1), 32-47.

Desmet, P., Overbeeke, K., \& Tax, S. (2001). Designing products with added emotional value: Development and appllcation of an approach for research through design. The design journal, 4(1), 32-47.

Diener, E., Fujita, F., \& Sandvik, E. (1994). What subjective well-being researchers can tell emotion researchers about affect. In Proceedings of the 8th Conference of the International Society for Research on Emotion (pp. 30-35). Storrs, CT: ISRE Publications.

Djamasbi, S., \& Strong, D. M. (2008). The effect of positive mood on intention to use computerized decision aids. Information \& Management, 45(1), 43-51.

Djamasbi, S., Strong, D., \& Dishaw, M. (2010). Affect and Acceptance: Examining the Effects of Positive Mood on Technology Acceptance Model. Decision Support Systems, 48(2), 383-394.

D'Mello, S., \& Graesser, A. (2009). Automatic detection of learner's affect from gross body language. Applied Artificial Intelligence, 23(2), 123-150.

Donato, G., Bartlett, M. S., Hager, J. C., Ekman, P., \& Sejnowski, T. J. (1999). Classifying facial actions. IEEE Pattern Analysis and Machine Intelligence, 21(10), 974-989.

Ekman, P. (1984). Expression and the nature of emotion. In K. Scherer, \& P. Ekman (Eds.), Approaches to Emotion (pp. 319-344). Erlbaum.

Ekman, P. (1992). An argument for basic emotions. Cognition and Emotion, 6, 169-200.

Ekman, P. (1994). Moods, emotions, and traits. In P. Ekman \& R. J. Davidson (Eds.), The nature of emotion, fundamental questions (pp. 56-58). Oxford: Oxford University press.

Ekman, P., \& Davidson, R. J (Eds.) (1994). The nature of emotion, fundamental questions. Oxford: Oxford University press.

Ekman, P., \& Friesen, W. (1978). Facial action coding system: A technique for the measurement of facial movement: Investigator's Guide 2 Parts. Sunnyvale: Consulting Psychologists Press.

Ekman, P., \& Friesen, W. V. (2003). Unmasking the Face. Cambridge: Malor Books.

Ekman, P., Levenson, R., \& Friesen, W. (1983). Autonomic nervous system activity distinguishes among emotions, Science, 221, 1208-1210.

El Kaliouby, R., Picard, R. W., \& Baron-Cohen, S. (2006). Affective computing and autism. Annals of the New York Academy of Sciences, 1093(1), 228-248.

Frijda, N. H. (1986). The emotions. Cambridge: Cambridge University Press.

Frijda, N. H. (1994). Varieties of affect: emotions and episodes, moods, and sentiments. In P. Ekman \& R. J. Davidson (Eds.), The nature of emotion, fundamental questions (pp. 59-67). Oxford: Oxford University press.

Girard, S., \& Johnson, H. (2009). Developing affective educational software products: Sorémo, a new method for capturing emotional states. Journal of Engineering Design, 20(5), 493-510.

Gorn, G. J., Goldberg, M. E., \& Basu, K. (1993). Mood, awareness, and product evaluation. Journal of Consumer Psychology, 2(3), 237-256.

Grove, J. R., \& Prapavessis, H. (1992). Preliminary evidence for the reliability and validity of an abbreviated Profile of Mood States. International Journal of Sport Psychology, 23, 93-109. 
Hashemian, M., Nikoukaran, A., Moradi, H., Mirian, M. S., \& Tehrani-doost, M. (2014). Determining mood using emotional features. In Telecommunications (IST), 2014 7th International Symposium on (pp. 418-423). Los Alamitos: IEEE.

Hernandez, J., Paredes, P., Roseway, A., \& Czerwinski, M. (2014). Under pressure: sensing stress of computer users. In Proceedings of the 32nd Annual ACM Conference on Human Factors in Computing Systems (pp. 51-60). New York: ACM.

Hilbolling, S., Hoogreef, P., Bospoort, L. van der, Vermeeren, B., Rierbroek, J., \& Goedegebuure, K. (2012). Mood transitions of delayed international passengers at Amsterdam Airport. Unpublished research report. Delft: Delft University of Technology.

Hilbolling, S., Prasasta Umaritomo, D., Christiaanse, T. J. H., Izaguirre, M., \& Lin, Y. C. (2011). Observation track 2011 : Emotions in High-Tech Products - GPS Car Navigation. Unpublished research report. Delft: Delft University of Technology.

Holland, J. (2011) (Ed.). Cabin illumination: in the mood for a brighter future. Aircraft Technology, Engineering \& Maintenance, 114, 34-40.

Hoque, M. E., El Kaliouby, R., \& Picard, R. W. (2009). When human coders (and machines) disagree on the meaning of facial affect in spontaneous videos. In Z., Ruttkay, M., Kipp, A. Nijholt, \& H. H. Vilhjálmsson (Eds.), Intelligent Virtual Agents (pp. 337-343). Amsterdam: Springer.

Huisman, G., \& Van Hout, M. (2010). The development of a graphical emotion measurement instrument using caricatured expressions: the LEMtool. In C. Peter, E. Crane, M. Fabri, H. Agius \& L. Axelrod (Eds.), Emotion in HCI - Designing for People. Proceedings of the 2008 International Workshop (pp. 5-8). Rostock: Fraunhofer.

Hupont, I., Lebreton, P., Maki, T., Skodras, E., \& Hirth, M. (2014). Is affective crowdsourcing reliable?. In Communications and Electronics (ICCE), 2014 IEEE Fifth International Conference on (pp. 516-521). Los Alamitos: IEEE.

Isbister, K., Höök, K., Sharp, M., \& Laaksolahti, J. (2006). The sensual evaluation instrument: developing an affective evaluation tool. In Proceedings of the SIGCHI conference on Human Factors in computing systems (pp. 11631172). New York: ACM.

Izard, C. E. (1991). The psychology of emotions. New York: Plenum Press.

Izard, C. E. (1993). The differential emotions scale; a method of measuring the meaning of subjective experience of discrete emotions. Newark: University of Delaware.

Ji, Q. (2007). A prototype emotional mouse for non-intrusive acquisition of physiological and behavioral data. Retrieved from http://www.ecse.rpi.edu/homepages/qji/HCI/mouse.html [Accessed 24 Feb. 2015].

Jimenez Garcia, J. , Romero, N., Keyson, D., \& Havinga, P. (2014). An Integrated Patient-Centric Approach for Situated Research on Total Hip Replacement: ESTHER. In Pervasive Health (pp. 343-365). London: Springer.

Jimenez Garcia, J., Romero, N. A., Boerema, S. T., Keyson, D., \& Havinga, P. (2013). ESTHER: a portable sensor toolkit to collect and monitor total hip replacement patient data. In Proceedings of the 3rd ACM MobiHoc workshop on Pervasive wireless healthcare (pp. 7-12). New York: ACM.

Jimenez, J., Romero, N., \& Keyson, D. (2011). Capturing patients' daily life experiences after total hip replacement. Paper presented at PervasiveHealth: 5th International Conference on Pervasive Computing Technologies for Healthcare [CD-ROM], 23-26 May 2011, Dublin.

Johnstone, T., van Reekum, C. M., Hird, K., Kirsner, K., \& Scherer, K. R. (2005). Affective speech elicited with a computer game. Emotion, 5(4), 513.

Kelley, S. W., \& Hoffman, K. D. (1997). An investigation of positive affect, prosocial behaviors and service quality. Journal of Retailing, 73(3), 407-427. 
Lang, P. J. (1980). Behavioural treatment and bio-behavioural assessment: computer applications. In J. B. Sidowski, J. H. Johnson, \& T. A. Williams (Eds.), Technology in mental health care delivery system (pp. 129-139). Norwood: Albex.

Laurans, G. (2011). On the moment-to-moment measurement of emotion during person-product interaction: by means of video-supported retrospective self-report, with some ancillary remarks on other issues in design-related emotion measurement (unpublished doctoral thesis). Delft University of Technology, Delft, The Netherlands.

Laurans, G. F. G., \& Desmet, P. M. A. (2012, September). Introducing PREMO2: New directions for the non-verbal measurement of emotion in design. In Out of Control: Proceedings of the 8th International Conference on Design and Emotion, London, UK, 11-14 September 2012.

Lazarus, R. (1991). Emotion and adaptation. Oxford: Oxford University Press.

Lazarus, R. (1994). The stable and the unstable in emotion. In P. Ekman \& R. J. Davidson (Eds.), The nature of emotion, fundamental questions (pp. 79-85). Oxford: Oxford University press.

Li, I., Dey, A. K., \& Forlizzi, J. (2011). Understanding my data, myself: supporting self-reflection with ubicomp technologies. In Proceedings of the 13th international conference on ubiquitous computing (pp. 405-414). New York: ACM.

LiKamWa, R., Liu, Y., Lane, N. D., \& Zhong, L. (2013, June). MoodScope: Building a mood sensor from smartphone usage patterns. In Proceeding of the 11th Annual International Conference on Mobile systems, Applications, and Services (pp. 389-402). New York: ACM.

Lin, Y. (2011). A natural contact sensor paradigm for nonintrusive and real-time sensing of biosignals in humanmachine interactions. IEEE Sensors Journal, 11(3), 522-529.

Lin, Y. Leng, H. Yang, G and Cai, H (2007). An intelligent noninvasive sensor for driver pulse wave measurement, IEEE Sensors Journal, 7(5), 790-799.

Littlewort, G., Whitehill, J., Wu, T., Fasel, I., Frank, M., Movellan, J., \& Bartlett, M. (2011). The computer expression recognition toolbox (CERT). In IEEE International Conference on Automatic Face \& Gesture Recognition and Workshops, 21-25 March 2011, Santa Barbara, CA (pp. 298-305). Los Alamitos: IEEE.

Lorr, M., \& McNair, D. M. (1988). Profile of mood states; bi-polar form (POMS-BI). San Diego: Educational and Industrial Testing Service.

Lorr, M., McNair, M. D., \& Fisher, S. (1982). Evidence for bipolar mood states. Journal of Personality Assessment, 46, 432-436.

MacLean, D., Roseway, A., \& Czerwinski, M. (2013). MoodWings: a wearable biofeedback device for real-time stress intervention. In Proceedings of the 6th International Conference on Pervasive Technologies Related to Assistive Environments (p. 66). New York: ACM.

Maier, E., Wilken, R., Schneider, H., \& Schneider, G.K. (2012). In the mood to buy? Understanding the interplay of mood regulation and congruence in an international context. Marketing Letters, 23(4), 1005-1018.

Manassis, K., Mendlowitz, S., Kreindler, D., Lumsden, C., Sharpe, J., Simon, M. D., Woolridge, N., Monga, S. and AdlerNevo, G. (2009). Mood assessment via animated characters: A novel instrument to evaluate feelings in young children with anxiety disorders. Journal of Clinical Child \& Adolescent Psychology, 38(3), 380-389.

Martin, L. L, \& Clore, G. L (2013). (Eds.) Theories of mood and cognition: A user's guidebook. Hove: Psychology Press.

Matthews, G., Jones, D. M., \& Chamberlain, A. G. (1990). Refining the measurement of mood: The UWIST mood adjective checklist. British Journal of Psychology, 81, 17-42.

Mayer, J. D., \& Salovey, P. (1988). Personality moderates the interaction of mood and cognition. Affect, cognition, and social behavior, 87-99. 
McDuff, D., Karlson, A., Kapoor, A., Roseway, A., \& Czerwinski, M. (2012). AffectAura: an intelligent system for emotional memory. In Proceedings of the SIGCHI Conference on Human Factors in Computing Systems, Austin, TX, USA, 05-10 May 2012 (pp. 849-858). New York: ACM.

McNair, D. M., Lorr, M., \& Droppleman, L. F. (1971). Manual for the profile of mood states. San Diego: Educational and Industrial Testing Services.

Mehrabian, A. (1996). Pleasure-arousal-dominance: A general framework for describing and measuring individual differences in temperament. Current Psychology, 14(4), 261-292.

Miniard, P. W., Bhatla, S., \& Sirdeshmukh, D. (1992). Mood as a determinant of postconsumption product evaluations: Mood effects and their dependency on the affective intensity of the consumption experience. Journal of Consumer Psychology, 1(2), 173-195.

Morris, M. E., \& Guilak, F. (2009). Mobile heart health: Project highlight. IEEE Pervasive Computing, 8(2), 57-61.

Morris, W. N. (1999). The mood system. In D. Kahneman \& E. Diener (Eds.), Well-being: The foundations of hedonic psychology (pp. 169-189). New York: Russell Sage Foundation.

Mota, S., \& Picard, R. W. (2003). Automated posture analysis for detecting learner's interest level. In Proceedings of the IEEE Computer Society Conference on Computer Vision and Pattern Recognition (CVPR), 18-20 June 2003, Madison Wisconsin, USA (pp. 49-49). Los Alamitos: IEEE.

Nowlis, V. (1965). Research with mood adjective checklist. In S. S. Tomkins \& C. E. Izard (Eds.), Affect, Cognition, and Personality. New York: Springer-Verlag.

Nowlis, V., \& Nowlis, H. H. (1956). The description and analysis of mood. Annals of the New York Academy of Science, 65, 345-355.

Ortony, A., \& Turner, T. J. (1990). What's basic about basic emotions?. Psychological review, 97(3), 315-331.

Parkinson, B., Totterdell, P., Briner, R. B., \& Reynolds. S. (1996). Changing moods: The psychology of mood and mood regulation. London: Longman.

Pascual, A., Ribera, M., \& Granollers, T. (2014a). Impact of web accessibility barriers on users with hearing impairment. In Proceedings of the XV International Conference on Human Computer Interaction (p. 8). New York: ACM.

Pascual, A., Ribera, M., Granollers, T., \& Coiduras, J. L. (2014b). Impact of accessibility barriers on the mood of blind, low-vision and sighted users. Procedia Computer Science, 27, 431-440.

Pasman, G. J., \& Romero Herrera, N. A. (2013). Applying experience reports in design education: Challenges and ideas. In E\&PDE 2013: International Conference on Engineering and Product Design Education, Dublin, Ireland, 5-6 September 2013. Dublin Institute of Technology (DIT).

Peeters, F., Berkhof, J., Delespaul, P., Rottenberg, J., \& Nicolson, N. A. (2006). Diurnal mood variation in major depressive disorder. Emotion, 6, 383-391.

Philips (2008). First commercial rollout Ambient Experience with citizenM hotels pioneers new direction for hospitality industry [Press release]. Retrieved from http://www.newscenter.philips.com/main/standard/about/news/press/20080624_citizen_m.wpd [Accessed 24 Feb. 2015].

Picard, R. W., \& Daily, S. B. (2005). Evaluating affective interactions: Alternatives to asking what users feel. In CHI 2005 Workshop on Evaluating Affective Interfaces: Innovative Approaches (pp. 2119-2122). New York: ACM.

Picard, R.W., \& Healey, J. (1997). Affective wearables. Personal Technologies,1(4), 231-240.

Poels, K., \& Dewitte, S. (2006). How to capture the heart? Reviewing 20 years of emotion measurement in advertising. Leuven: Katolieke Universiteit Leuven. 
Pollak, J. P., Adams, P., \& Gay, G. (2011). PAM: a photographic affect meter for frequent, in situ measurement of affect. In Proceedings of the SIGCHI conference on Human factors in computing systems (pp. 725-734). New York: ACM.

Prinz, J. J. (2004). Gut reactions: A perceptual theory of emotions. Oxford: Oxford University Press.

Quartier, K., Christiaans, H., \& Van Cleempoel, K. (2009). Retail design: lighting as an atmospheric tool, creating experiences which influence consumers' mood and behaviour in commercial spaces. In D. Durling, C. Rust, L. L. Chen, P. Ashton, \& K. Friedman (Eds.), Undisciplined! Proceedings of the Design Research Society Conference 2008 [CD-ROM]. Sheffield: Sheffield Hallam University.

Read, J. C. (2008). Validating the Fun Toolkit: an instrument for measuring children's opinions of technology. Cognition, Technology \& Work, 10(2), 119-128.

Rogers, Y. (2011). Interaction design gone wild: striving for wild theory. Interactions, 18(4), 58-62.

Russell, J. A. (1979). Affective space is bipolar. Journal of Personality and Social Psychology, 37, 1152-1168

Russell, J. A. (1980). A circumplex model of affect. Journal of Personality and Social Psychology, 39, 1161-1178.

Russell, J. A. (2003). Core affect and the psychological construction of emotion. Psychological Review, 110(1), 145-172.

Russell, J. A., Weiss, A., \& Mendelsohn, G. A. (1989). Affect grid: a single-item scale of pleasure and arousal. Journal of personality and social psychology, 57(3), 493.

Sánchez, J. A., Hernández, N. P., Penagos, J. C., \& Ostróvskaya, Y. (2006, November). Conveying mood and emotion in instant messaging by using a two-dimensional model for affective states. In Proceedings of VII Brazilian symposium on Human factors in computing systems (pp. 66-72). New York: ACM.

Sauter, D. A., Eisner, F., Calder, A. J., \& Scott, S. K. (2010). Perceptual cues in nonverbal vocal expressions of emotion. The Quarterly Journal of Experimental Psychology, 63(11), 2251-2272.

Sauter, D. A., McDonald, N. M., Gangi, D. N., \& Messinger, D. S. (2014). Nonverbal expressions of positive emotions. In M. M. Tugade, M. N. Shiota, \& L. D. Kirby (Eds.), Handbook of Positive Emotions (pp. 179-198). New York: Guilford Press.

Scherer, K. R. (2005). What are emotions? And how can they be measured? Social science information, 44(4), 695-729.

Schwarz, N., \& Clore, G. L. (2003). Mood as information: 20 years later. Psychological Inquiry, 14(3-4), 296-303.

Spillers. F. (2010). Getting in the Mood: The role of mood in product design and interaction. in Proceedings of the 7 th International Conference on Design and Emotion [CD-ROM], Chicago, USA, 4-7 October 2010. Chicago: IIT institute of Design.

Stylios, G. K., \& Yang, D. Y. (2013). The concept of mood changing garments made from luminescent woven fabrics and flexible photovoltaics: MoodWear. Advances in Science and Technology, 80, 22-29.

Sun, D., Paredes, P., \& Canny, J. (2014). MouStress: Detecting stress from mouse motion. In Proceedings of the 32nd Annual ACM Conference on Human Factors in Computing Systems (pp. 61-70). New York: ACM.

Terry P. C., Lane A. M., Lane H. J., \& Keohane L. (1999). Development and validation of a mood measure for adolescents. Journal of Sports Science, 7, 861-872.

Terry, P. C., \& Lane, A. M. (2003). User Guide for the Brunel Mood Scale (BRUMS). Unpublished manuscript.

Terry, P. C., Lane, A. M., Lane, H. J., \& Keohane, L. (1999). Development and validation of a mood measure for adolescents. Journal of Sports Sciences, 17(11), 861-872.

Terzis, V., Moridis, C.N., \& Economides, A. A. (2010). Measuring instant emotions during a self-assessment test: the use of FaceReader. In Proceedings of the 7th International Conference on Methods and Techniques in Behavioral Research, August 24-27, 2010, Eindhoven, The Netherlands (pp. 18-28). New York: ACM.

Thayer, R. E. (1967). Measurement of activation through self-report monograph supplement 1-V20. Psychological reports, 20(2), 663-678. 
Thrasher, M., Van der Zwaag, M. D., Bianchi-Berthouze, N., \& Westerink, J. H. (2011). Mood recognition based on upper body posture and movement features. In J. Luo (Ed.), Affective computing and intelligent interaction, Vol. 137 (pp. 377-386). Berlin Heidelberg: Springer.

Van Dale (2009). Van Dale Grote Woordenboeken, version 5.0. Utrecht: Van Dale Publishers

Van de Garde, E. (2014). GRIP relaxation space. Retrieved from: http://www.crispplatform.nl/news/grip-relaxationspace [Accessed 24 Feb. 2015].

Vastenburg, M. H., \& Romero, N. (2011). Experience tags: enriching sensor data in an awareness display for family caregivers. In: D. Keyson \& B. Kröse (Eds.), AmI 2011, LNCS 7040. (pp. 285-289). Berlin Heidelberg: SpringerVerlag.

Vastenburg, M. H., Keyson, D. V., \& Ross, P. (2007). A user experience-based approach to home atmosphere control. Universal Access in the Information Society 6(1), 1-13.

Venkatesh, V., \& Speier, C. (1999). Computer technology training in the workplace: A longitudinal investigation of the effect of mood. Organizational Behavior and Human Decision Processes, 79(1), 1-28.

Verduyn, P., Van Mechelen, I., \& Tuerlinckx, F. (2011). The relation between event processing and the duration of emotional experience. Emotion, 11(1), 20-28.

Villa, B. J., De Moor, K., Heegaard, P. E., \& Instefjord, A. (2014). Investigating Quality of Experience in the context of adaptive video streaming: findings from an experimental user study. Norsk informatikkonferanse (NIK), 2013.

Watson, D. (1988). The vicissitudes of mood measurement: Effects of varying descriptors, time frames, and response formats on measures of positive and negative affect. Journal of Personality and Social Psychology, 55, 128-141.

Watson, D., \& Clarck, L. A. (1994). The PANAS-X; manual for the positive and negative affect schedule-expanded form. Iowa: The University of Iowa.

Watson, D., \& Tellegen, A. (1985). Towards a consensual structure of mood. Psychological Bulletin 98(2), 219-235.

Watson, D., Clark, L. A., \& Tellegen, A. (1988). Development and validation of brief measures of positive and negative affect: The PANAS Scales. Journal of Personality and Social Psychology, 54(6), 1063-1070.

Wensveen, S., Overbeeke, K., \& Djajadiningrat, T. (2002). Push me, shove me and I show you how you feel: recognising mood from emotionally rich interaction. In Proceedings of the 4th Conference on Designing Interactive Systems: Processes, Practices, Methods, and Techniques (pp. 335-340). New York: ACM.

Zeng, Z., Pantic, M., Roisman, G. I., \& Huang, T. S. (2009). A survey of affect recognition methods: Audio, visual, and spontaneous expressions. IEEE Transactions on Pattern Analysis and Machine Intelligence, 31(1), 39-58.

Zhang, M., \& Jansen, B. J. (2009). Influences of mood on information seeking behavior. In CHI'09 Extended Abstracts on Human Factors in Computing Systems (pp. 3395-3400). New York: ACM.

Zimmermann, P., Guttormsen, S., Danuser, B., \& Gomez, P. (2003). Affective computing-a rationale for measuring mood with mouse and keyboard. International Journal of Occupational Safety and Ergonomics, 9(4), 539-551.

Zuckerman, M., \& Lubin, B. (1985). Manual for the MAACL-R: The multiple affect adjective check list revised. San Diego: Educational and Industrial Testing Service.

\section{Appendix 1; Verbal self-report methods to measure affect}

\begin{tabular}{|l|l|l|l|l|l|l|}
\hline Method & Full name & $\begin{array}{l}\text { Key } \\
\text { reference }\end{array}$ & $\begin{array}{l}\text { Factors } \\
\text { vs. types }\end{array}$ & Items & Description & Factors / emotions measured \\
\hline BRUMS & $\begin{array}{l}\text { Brunel Mood } \\
\text { Scale }\end{array}$ & $\begin{array}{l}\text { Terry \& } \\
\text { Lane, 2003 }\end{array}$ & Types & & $\begin{array}{l}\text { Measures 6 mood states } \\
\text { with item sample of 24 } \\
\text { adjectives. } \\
\text { Measures same states as } \\
\text { POM. }\end{array}$ & $\begin{array}{l}\text { Anger, confusion, depression, fatigue, } \\
\text { tension, and vigour. }\end{array}$ \\
\hline DES & Differential & Izard, & Types & adjectives & Measures 10 emotions, each & Interest, joy, surprise, sadness, anger, \\
\hline
\end{tabular}




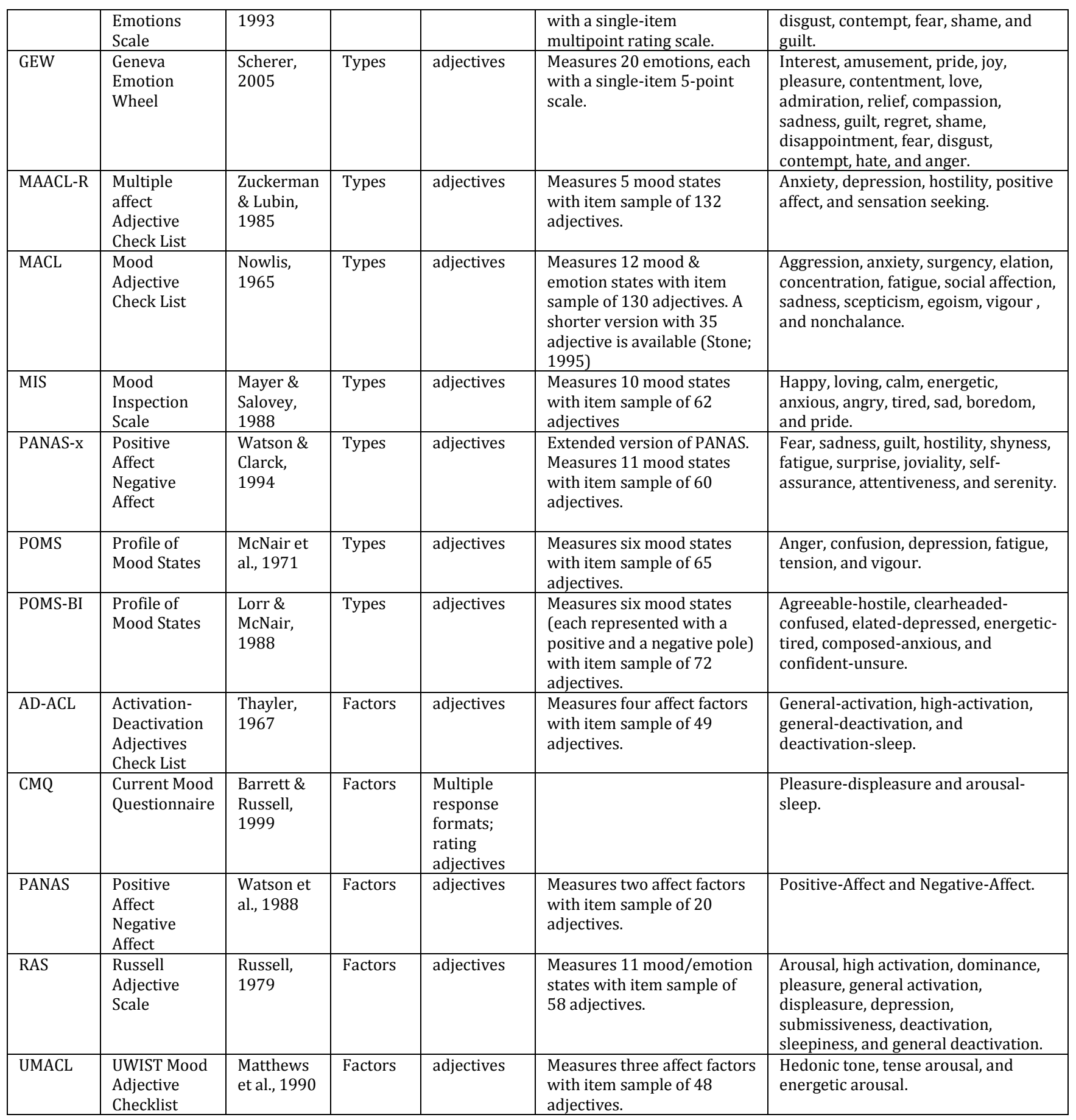

\section{Appendix 2; Pictorial self-report methods to measure affect}

\begin{tabular}{|l|l|l|l|l|l|l|}
\hline Method & Full name & $\begin{array}{l}\text { Key } \\
\text { reference }\end{array}$ & $\begin{array}{l}\text { Factors } \\
\text { vs. types }\end{array}$ & Items & Description \\
\hline GLS & $\begin{array}{l}\text { Gaston } \\
\text { Lagaffe Scale }\end{array}$ & $\begin{array}{l}\text { Johnstone } \\
\text { et al., 2005 }\end{array}$ & Types & $\begin{array}{l}\text { Static cartoon } \\
\text { characters }\end{array}$ & $\begin{array}{l}\text { French comic-strip } \\
\text { character expressing } \\
\text { eight emotions. Strength } \\
\text { with 100-point graphic } \\
\text { scale. }\end{array}$ & $\begin{array}{l}\text { Interest, joy, surprise, anger, } \\
\text { shame, pride, tenseness, and } \\
\text { helplessness. }\end{array}$ \\
\hline Pick-A-Mood & Pick-A-Mood & $\begin{array}{l}\text { This } \\
\text { manuscript }\end{array}$ & Types & $\begin{array}{l}\text { Static cartoon } \\
\text { characters }\end{array}$ & $\begin{array}{l}\text { Three characters } \\
\text { expressing eight basic } \\
\text { mood types }\end{array}$ & $\begin{array}{l}\text { Excited-lively, cheerful-happy, } \\
\text { relaxed-carefree, calm-serene, } \\
\text { bored-weary, sad-gloomy, irritated- } \\
\text { annoyed, and tense-nervous. }\end{array}$ \\
\hline LEM & $\begin{array}{l}\text { Layered } \\
\text { Emotion }\end{array}$ & $\begin{array}{l}\text { Huisman \& } \\
\text { van Hout, }\end{array}$ & Types & $\begin{array}{l}\text { Static cartoon } \\
\text { characters }\end{array}$ & $\begin{array}{l}\text { One character expressing } \\
\text { 8 interactive media }\end{array}$ & $\begin{array}{l}\text { Joy, desire, fascination, satisfaction, } \\
\text { sadness, disgust, boredom, and }\end{array}$ \\
\hline
\end{tabular}




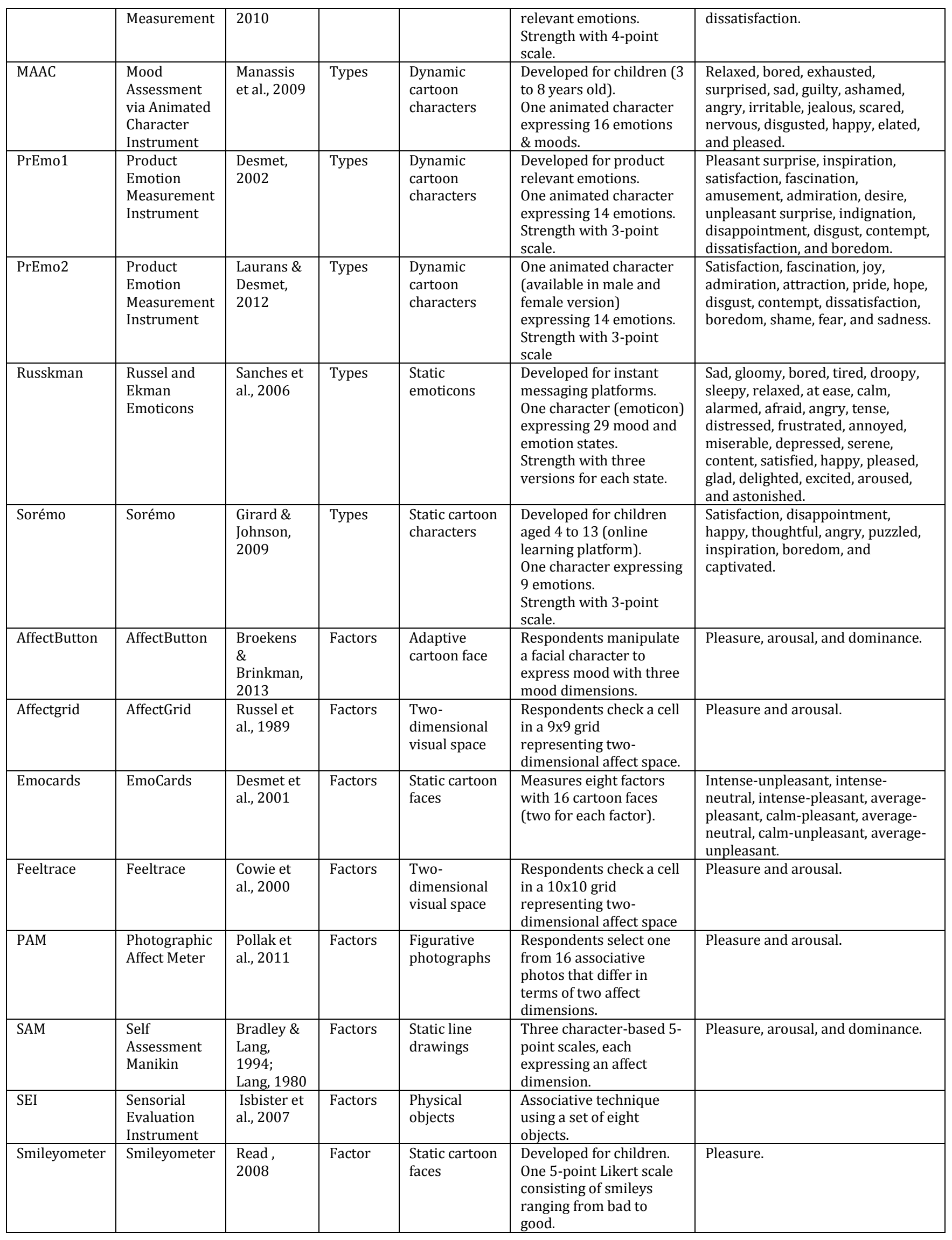


i Earlier versions were reported by Desmet, Vastenburg, Van Bel, and Romero Herrera (2012).

ii Over 20 years ago, Ekman and Davidson (1994) published a seminal work on 'the nature of emotion.' In this edited book they invited key theorists of emotion to reflect on 12 questions about human emotion. The second question focused on the difference between emotion and mood, and was addressed by eight authors, including Paul Ekman, Richard Lazarus and Nico Frijda. The key differences included in Table 1 were based on these discussions, which, today, still represent a key resource for understanding the differences between mood and emotion.

iii Although examples of specific instruments are provided, each approach is discussed as a category of methods. For in-depth reviews of methods within categories see Bailenson et al. (2008), Calvo and D'Mello (2010), Coan and Allen (2007), Lin (2011), and Zeng et al. (2009). 